\title{
Nanoparticle Characterization of Traditional Homeopathically- Manufactured Silver (Argentum Metallicum) Medicines and Placebo Controls
}

\author{
Iris R Bell1,2,3*, Subra Muralidharan ${ }^{4}$ and Gary E Schwartz ${ }^{5}$ \\ ${ }^{1}$ Department of Family and Community Medicine, University of Arizona College of Medicine, Tucson, AZ USA \\ ${ }^{2}$ College of Nursing, University of Arizona, Tucson, AZ USA \\ ${ }^{3}$ The American Medical College of Homeopathy, Phoenix, AZ USA \\ ${ }^{4}$ Department of Molecular and Cellular Biology, University of California Davis, CA USA \\ ${ }^{5}$ Department of Psychology, University of Arizona, Tucson, AZ USA
}

\begin{abstract}
This exploratory study characterized nanoparticles (NPs) in homeopathically-prepared silver medicine (Argentum Metallicum), succussed and unsuccussed control solutions. Methods included nanoparticle tracking analysis (NTA), zeta potentials, inductively-coupled plasma mass spectroscopy (ICP-MS) for silver, and ultraviolet visible spectroscopy (UV-vis). Homeopathy is a 200 year-old traditional medical system using mineral, plant, and animal sources to treat patients. Debate over the efficacy of homeopathic medicines (HMs) stems from its unique manufacturing methods involving dry milling in lactose and/or serial dilutions and succussions (intense agitation) in water or water-ethanol solvent. The present study examined commercially-made, randomized and blinded verum Argentum Metallicum HMs and succussed solvent controls at $6 \mathrm{C}, 30 \mathrm{C}$, and $200 \mathrm{C}$ potencies, and unsuccussed solvent $(95 \% \mathrm{v} / \mathrm{v}$ ethanol) in corkstoppered glass vials. NTA revealed $>2 \times 10^{8} \mathrm{NPs} / \mathrm{ml}$ in 20 of 21 samples, with extensive polydispersity. Verum NP characteristics differed significantly from controls: (a) Although Verum $200 \mathrm{C}$ exhibited the highest NP concentrations and exemplar transmission electron microscopy of one Verum 30C sample showed scattered silver-like dark NPs embedded in an organic matrix, ICP-MS could not reliably detect elemental silver at $1 \mathrm{ppb}$ (lower limits of instrument detection); (b) verum NPs were significantly larger sized across potencies $(91 \mathrm{~nm})$ versus unsuccussed controls $(53 \mathrm{~nm})$; (c) zeta potentials of verum NPs (mean $-44 \mathrm{mV}$ ) were significantly more negative than the unsuccussed controls (mean $-20 \mathrm{mV}$ ); (d) succussed controls were intermediate in NP concentrations and sizes between verums and unsuccussed controls; (e) All samples showed UV-vis absorbance peaks near 200-350 nm wavelengths, consistent with organic cork extract. Taken together, the findings suggest polydisperse heterogeneous nanohybrid mixtures of silver, silica shell/ silver core, silica NPs, and perhaps cork exosomes, self-assembled and surface-stabilized by silica coatings, organic plant extract (cork), and/or lactose in verums. Glassware-derived silica from succussions may contribute NPs and coatings for nonlinear source signal amplification to initiate clinical effects.
\end{abstract}

Keywords: Nanoparticles; Silver; Silica; Quercus suber; Homeopathy; Nanoparticle tracking analysis; Zeta potential; Ultraviolet visible spectroscopy; Transmission electron microscopy; ICP-MS

\section{Introduction}

Recent studies indicate that homeopathically-prepared medicines (HMs) contain source nanoparticles (NPs) [1-9], silicates [3,5,1012], and other less well characterized nanostructures. Homeopathy is an over 200-year-old system of traditional medicine widely used in countries such as India, Germany, France, Belgium, the UK, and across Latin America for many different chronic and acute conditions including autoimmune, allergic, and infectious diseases $[13,14]$. Some doctors in India use homeopathic medicines to treat people with various cancers as well $[15,16]$. Nonetheless, skeptics continue to insist that HMs are merely placebos containing no source material and no active material in any form [17].

From its inception, the field has generated debate over the nature of its medicines because of one aspect of its manufacturing methods, i.e., serial dilutions. For example, to produce metal-derived medicines from insoluble sources (such as Argentum Metallicum (silver)), these methods involve initial prolonged dry milling or grinding of source material in lactose followed by serial dilutions in water or ethanolwater diluent (e.g., in ratios of $1 / 10$, designated by "X potency," or $1 / 100$, designated by "C potency") with each dilution step followed by multiple succussions, e.g., 10-100 per dilution step. Succussions are rapid, repetitive up-and-down agitations via vertical strokes of the borosilicate glassware containing the solution against a hard elastic surface or vortexing. Skeptics have focused on the dilutions beyond Avogadro's number for bulk form source materials and ignored the trituration and succussion steps as well as their potential contributions to the final product [18].

Nanotechnology researchers have begun to recognize the overlaps between the traditional crude mechanical attrition manufacturing techniques of homeopathy and top down approaches for making nanostructures from insoluble source materials in modern nanotechnology. Using transmission electron microscopy (TEM), Chikramane et al. [2] first reported finding specific, irregularlyshaped polydisperse source metal nanoparticles (concentration range of picograms $/ \mathrm{ml}$ to nanograms $/ \mathrm{ml}$ ) in six different commercially-

*Corresponding author: Iris $\mathrm{R}$ Bell, $\mathrm{MD} \mathrm{PhD}$, Department of Family and Community Medicine, The University of Arizona College of Medicine, $1450 \mathrm{~N}$ Cherry Avenue, MS 245052,Tucson, AZ 85719, USA, Tel: 520906 6767; Fax:520 749 4509; E-mail: ibell@email.arizona.edu

Received June 10, 2015; Accepted July 02, 2015; Published July 12, 2015

Citation: Bell IR, Muralidharan S, Schwartz GE (2015) Nanoparticle Characterization of Traditional Homeopathically-Manufactured Silver (Argentum Metallicum) Medicines and Placebo Controls. J Nanomed Nanotechnol 6: 311. doi:10.4172/2157-7439.1000311

Copyright: (C) 2015 Bell IR, et al. This is an open-access article distributed under the terms of the Creative Commons Attribution License, which permits unrestricted use, distribution, and reproduction in any medium, provided the original author and source are credited. 
made metal HMs. NP sizes in the HMs were generally less than 15 nanometers in size with no potency-related size differences. Estimated metal source concentrations with inductively-coupled plasma atomic emission spectroscopy (ICP-AES) testing after extensive preconcentration procedures ranged from the 30.6 picograms/milliliter (pg/ml) or less for silver, up to $3990 \mathrm{pg} / \mathrm{ml}$ for zinc. Findings differed between manufacturers and between batches within manufacturers.

Critics of the latter study objected to the lack of published controls and raised questions about why the average metal nanoparticle sizes, though polydisperse, reportedly did not differ between potencies despite increasing numbers of succussions over increasing potencies in the original Chikramane et al. TEM study. In a follow up study with controls, Chikramane et al. [1] used modern manufactured monodisperse gold nanoparticles prepared homeopathically with an initial trituration (grinding) process in lactose followed by serial dilutions and succussions in $90 \% \mathrm{v} / \mathrm{v}$ ethanol solutions up to $15 \mathrm{C}$ potencies (theoretically past Avogadro's number of molecules for removal of all bulk source materials).

They demonstrated the heterogeneous accumulation of the lactosemilled gold NPs in layers near the top of the succussed solutions and the transfer of the same-sized nanoparticles coated in lactose across consecutive potencies, with an asymptote in particle concentrations starting at $6 \mathrm{C}$. Lactose and bubble formation appeared key to facilitating the accumulation and transfer of the gold NPs. Bulk source material appeared to be gradually removed, but nanostructures persisted.

Subsequent independent studies in seven other laboratories using electron microscopy, atomic force microscopy, dynamic light scattering (DLS), or nuclear magnetic resonance (NMR) procedures have replicated the presence of nanostructures in homeopathicallyprepared medicines made from six different plants $[3,4,8]$, two modern synthetic drugs [7], several other different organic source materials (alpha-tocopherol, potassium phenosan, ichfan C-10) [9], silica and lactose [5,19], and even succussed solvent [6]. These nanostructures appeared at homeopathic potencies seemingly diluted for bulk source forms beyond Avogadro's number of molecules (24X or $12 \mathrm{C}$ potencies and higher). A separate research group showed that four different homeopathic plant extracts (mother tinctures) can generate biologically-active silver nanoparticles from silver nitrate at room temperature [20].

In addition, five laboratories reported silica and nanosilica from silicates in the parts per million range (ppm), released into solution by homeopathic manufacturing succussions or conventional vortexing in glassware $[3,5,10,21,22]$. In vitro studies have shown biological activity of homeopathically succussed control solutions at a magnitude intermediate between that of verum medicines and unsuccussed controls [23]. Other laboratories found aging phenomena in homeopathic medicines stored at smaller volumes in solution and/ or tested at high $\mathrm{pH}[21,24,25]$. A separate body of research has shown that HMs have unique electromagnetic and optical signal properties in potencies, compared with controls [26-35].

The purpose of the present exploratory study was to replicate and extend colloidal NP characterization in commercial homeopathicallymade Argentum Metallicum(silver source) at 6C, 30C, and $200 \mathrm{C}$ potencies versus succussed and unsuccussed control solutions. Based on prior extensive literature reviews [36-40], as well as parallel nanotechnology studies on modern synthesis of tunable silver coresilica shell composite NPs made in ethanol with saccharides as reducing agent and electrostatic stabilizer [41], we hypothesized the presence of polydisperse NP mixtures of silver, silica-shell/silver-core, silverdoped silica, and coreless silica nanoparticles in verum homeopathic medicines versus mainly silica nanoparticles in succussed controls.

\section{Materials and Methods}

Rationale: Anticipating a need to detect low concentrations of polydisperse nanoparticles of different sizes, shapes, surface properties, and composition [2], we extended previous research by using the highly sensitive technology of nanoparticle tracking analysis (NTA) [42] as the primary outcome measure (see rationale below). To further characterize the nanoparticles, we measured zeta potentials, and ICPmass spectroscopy (ICP-MS) for silver. Finally, given past evidence of ultraviolet-visible spectroscopy (UV-vis) differences between homeopathic verum potencies and controls [31-35,43], we also evaluated UV-visible spectroscopic patterns. TEM was performed on one pre-concentrated verum $30 \mathrm{C}$ sample as an exemplar; budgetary limitations precluded further use of electron microscopy in this study. Although typically not done in mainstream nanotechnology studies, we randomized and blinded the contents of the specific sample vials for the analytical laboratories to eliminate operator bias during the testing procedures.

We chose silver as the initial source material for HMs because of the growing research literature on the potential clinical utility of engineered silver nanoparticles for cancer and infectious disease treatment [20,4450]. Silver has good optical contrast properties for visualization in TEM, NTA, and other NP characterization technologies and a welldescribed UV-vis wavelength range, including red-shift of silver surface plasmon resonance peaks from interactions with silica [51,52] Prior infrared and Raman spectroscopy and photoluminescence studies on homeopathically-prepared medicines have shown that the material retains a spectroscopic $[34,53,54]$ and photonic [28-30] "signature" of the original source material.

However, silicates in HMs and succussed controls [3,5,10,11,21,22] could adsorb onto container walls and silver NPs and self-assemble into various silica nanostructures [55]. Rather than being removed by serial dilution-succussion processes, repeated succussions would potentially add fresh nanosilica [22] and other elements, eg, sodium, boron [21], and mechanically knock some adsorbed nanostructures from glassware walls into solution for particle collisions at each manufacturing step [56]. Silica is well-established as a nanoelectronic signal amplifier [57-59], immune adjuvant in vaccines [60-62], and general biological amplifier [63-68], as well as colloidal and chemical stabilizer [41,69].

\section{Homeopathically-manufactured medicines}

The medicines and placebo controls were made by Hahnemann Laboratories, a commercial FDA-regulated U.S. homeopathic pharmacy specializing in supplying custom-made HMs to practitioners. They utilize materials and methods modeled after the original writings of Samuel Hahnemann, MD, the physician-chemist who first developed homeopathic medicines [70]. This manufacturer also follows published standardization procedures set by the Homeopathic Pharmacopoeia of the United States. Our group had used this company's medicines in multiple previously-published studies showing both in vitro $[34,71]$ and in vivo human preclinical/clinical [72-74] and electroencephalographic [75-77] differences between verums and placebo controls.

The pharmacy follows clean-room procedures at room temperature and pressure and uses a standardized mechanical arm mimicking a human arm to produce their succussions. As do most homeopathic manufacturers, they use Hahnemannian methods by transferring one 
part of the last succussed dilution into a fresh glass vial containing 99 parts solvent to perform the next serial dilution in liquid solvent to make a 6C potency. The Argentum Metallicum HMs were made from source silver powder obtained from Alfa Aesar Chemical Company (Ward Hill, MA USA). Because of limited solubility of silver powder, trituration (milling) and dry dilutions were done in lactose through the $3 \mathrm{C}$ potency.

To conserve glassware, homeopathic manufacturers routinely switch to a Korsakovian serial dilution method while making higher potencies after roughly the $15 \mathrm{C}-25 \mathrm{C}$ step (varies by manufacturer). The latter approach involves removing 99 parts of the last succussed dilution and adding 99 parts of fresh solvent into the same glassware containing the residual 1 part of the previous succussed dilution.

That is, $6 \mathrm{C}$ potencies would utilize different containers at each preparation step, whereas $30 \mathrm{C}$ and $200 \mathrm{C}$ potencies would be utilizing the same piece of glassware for every serial dilution-succussion step, from, eg, in this study with Hahnemann Laboratories' HMs, from 15C up to the final potency (30C or $200 \mathrm{C}$ ).

The manufacturer in this study made all of the placebo samples before making the verum Argentum Metallicum samples in this study to minimize the risk of cross-contamination. The manufacturer used clear borosilicate pharmacy quality glass $8 \mathrm{ml}$ containers (Acme Bottle and Glass Co., Inc, Paso Robles, CA USA) with natural cork stoppers (size 3, Zandur, Nottingham, PA USA) for their sample production of 5.5 milliliter samples at a time.

The manufacturer shipped a set of 21 total vials of the sample potencies and controls to each of two different analytical laboratories by overnight courier. The corked vials were covered with parafilm and packed securely prior to shipment to prevent leakage. Contents of each set included 3 separate vials of each of 3 different verum HM potencies (6C, 30C, 200C) (total verum $\mathrm{N}=9$ ) and their respective potentized (i.e., serially diluted and succussed ethanol-water only) placebo controls (total succussed controls $\mathrm{N}=9$ ), as well as 3 separate vials of unsuccussed (unpotentized) diluent (total unsuccussed controls $\mathrm{N}=3$ ). Diluent for all samples was $95 \% \mathrm{v} / \mathrm{v}$ pharmaceutical grade ethanol (Pharmco, USA) in double-distilled water.

For this initial study, we elected to make the succussed controls using only the ethanol-water rather than milled plain lactose in ethanolwater solvent. The rationale was that homeopathically-prepared lactose can be clinically active as a salient medicine for certain individuals [78] and mechanical milling can change the nanostructure of lactose per se [79]. We wanted lactose-free succussed controls that could be compared directly to unsuccussed controls for their potential silica or other nanostructures without a lactose confound.

The unsuccussed controls could not contain any lactose, even if it were to have dissolved. That is, stirring or shaking a lactosecontaining control vial to mix the material would add some degree of a "succussion" process to the preparation, thereby rendering such a control "succussed" and invalid. For the present exploratory study as a first step, we chose to treat the verum as a unitary composite of silver triturated (mechanically milled) in lactose, suspended in the solvent and compared with silver-free, lactose-free succussed and unsuccussed controls.

\section{Randomization and blinding}

The first author (IB) generated a spreadsheet of vials for production, used the list randomizer program at www.random.org to assign unique random vial code numbers to each sample, and emailed the code assignments to the manufacturer. The manufacturer applied labels on site with no other identifying information on each vial other than the unique number code. All placebo and verum samples were made between April 2-4, 2014 and shipped together directly from the manufacturer by overnight courier to the analytical laboratories (Northwestern University Core Laboratories, Evanston, IL, for NTA, zeta potential, and DLS tests; and Nanocomposix, San Diego, CA, for ICP-MS, UV-visible spectroscopy, and TEM tests).

The analytical laboratories tested the samples blinded and reported the findings only by vial number. The laboratories were told the ethanol concentration and that some samples might contain silver in order to calibrate their instruments appropriately. However, they ran the randomized and number coded samples in a blinded manner and received no information from the investigators or the manufacturer concerning the contents of any specific vial. Samples were stored at room temperature away from direct sunlight [33]. Based on clinical standards and past research [80], laboratories were asked to minimize the exposure of the samples to any external electromagnetic sources during storage.

\section{Nanoparticle Tracking Analysis (NTA)}

The nanoparticle tracking analysis testing was done in numeric order of the randomized vial number on all samples in triplicate per vial between mid-April and mid-May, 2014. NTA utilized the NanoSight LM 10-HS, with software version 2.3 (NanoSight/ Malvern, Malvern Worcestershire, UK). The equipment was located at the Northwestern University Keck Biophysics Core Facility, Evanston, IL USA. Particle size range detection is $10-1000 \mathrm{~nm}$ or larger per the manufacturer's manual. The majority of samples were run without requiring additional dilution to achieve a concentration range that the instrument can detect. However, some samples with higher concentrations of particles at the analytical laboratory required dilution at a ratio of $1: 2$ or $1: 10$ for testing purposes. Data reflect independent triplicate tests on each sample vial. Vials were tested with NTA in number coded sequence between April 15 through May 20, 2014.

Data include both quantitative assessments of each sample and 60 -second videos of the Brownian motion of nanoparticles in the samples. The videos were recorded at 25 frames/second with a $25 \mathrm{~ms}$ camera shutter at room temperature.

The rationale for using NTA primarily rather than TEM or DLS for this study was multifold: (a) Compared with DLS, NTA is reportedly more sensitive to low concentrations of NPs, (b) less susceptible than DLS to sizing artifacts in polydisperse samples from the presence of larger particles [81], (c) able to quantify NP concentrations without subjecting as-manufactured samples to drying or processing that could confound findings, and (d) able to utilize test materials in solutions of any solvent without requiring additional preparation steps. NTA correlates well with findings from transmission electron microscopy for silica NPs [81], can detect exosomes from animal or plant sources [82], and was a practical economic choice over TEM for running all of the intended number of samples in this small exploratory study. TEM is not only labor intensive and costly, but it also requires more sample processing and drying that NTA does not. TEM sample processing might introduce artificial changes into the dried samples.

\section{Zeta potential measurements}

The samples at Northwestern University were transferred locally from the NTA Keck Biophysics Core Laboratory directly to 
the Equipment Core Facility of the Simpson Querrey Institute at Northwestern University for additional characterization. The zeta potentials and DLS assessments were performed using a Zetasizer Nano ZSP (Malvern Instuments, Inc, USA) at $25^{\circ} \mathrm{C}$ with a scattering angle of $173^{\circ} \mathrm{C}$. Limits of particle size detection for this instrument per the manufacturer manual range from $0.3 \mathrm{~nm}$ to $10 \mu \mathrm{m}$. These tests were all performed on June 19-20, 2014.

\section{Inductively-Coupled Plasma Mass Spectrometry (ICP-MS)}

In a separate analytic laboratory (Nanocomposix, San Diego, CA), 21 duplicate samples were tested using a Thermo Fisher X Series 2 ICP-MS instrument, calibrated to detect silver. The blank control in this instrument showed a silver concentration of 0 up to extrapolated $0.014 \mathrm{ppb}$. The instrument's reliable lower limit of detection was approximately $1 \mathrm{ppb}$. Testing took place in mid-April to May, 2014. After finding multiple outlier values for silver in verums and controls, we requested repeat testing of only the 7 outliers, which was completed by July 3,2014 .

The ICP-MS analysis is complicated by the presence of ethanol and dispersed silica nanoparticles. Evaporation of the Argentum samples yielded silica solids probably containing Ag. The amount of solid obtained upon evaporation was higher for the higher potencies compared to the lower potencies. Reliable concentrations of Ag could not be obtained even by evaporation of the Argentum samples followed by dissolution of the solids in a mixture of $3 \% \mathrm{HNO}_{3}$ and $0.05 \% \mathrm{HF}$.

\section{Ultraviolet Visible spectrometry (UV-Vis)}

The same nanoparticle characterization laboratory (Nanocomposix, San Diego, CA) that performed the ICP-MS carried out the UV-Vis absorbance testing on all 21 vials. The instrument was an Agilent 8453 UV-visible spectrometer. Testing was performed in a quartz cuvette with a $1 \mathrm{~cm}$ path length. Testing took place in mid-April to May, 2014. Data reported encompassed the wavelength range of 190 to 1100 nanometers $(\mathrm{nm})$.

\section{Transmission Electron Microscopy (TEM)}

After the ICP-MS and UV-vis spectroscopy were completed and the final data reported, the investigators requested by vial number an exploratory TEM on one Verum 30C sample that had shown initial ICP-MS and UV-vis data consistent with the possible presence of silver nanoparticles. The Nanocomposix laboratory used a JEOL 1010 Transmission Electron Microscope after several days of sample preparation. Given the ICP-MS findings of inability to detect elemental silver reliably, the technician elected to pre-concentrate the sample prior to TEM. Over a 3-day period, he placed a series of 25 separate 10 -microliter drops from the sample vial on the test grid and air-dried them at room temperature by evaporation. As noted above, budgetary limitations precluded using TEM on any other additional samples.

\section{Statistical analysis}

Statistical analyses used Statistica Academic 12.0 software and included analyses of variance over all 7 possible types of samples (verum 6C, 30C, 200C; succussed controls 6C, 30C, 200C; unsuccussed controls) with post-hoc Tukey tests for subgroup comparisons when indicated. Planned comparisons were to compare all verum and succussed control samples at each potency against unsuccussed controls as well as comparing verum and succussed control samples with one another at each of their respective three different homeopathic potencies.

\section{Results}

\section{Nanoparticle tracking analysis}

NTA findings revealed the presence of nanoparticles in most samples, but unique particle characteristics for verum (more NPs in the 200C potency; larger sizes for all potencies) compared with unsuccussed controls. The verum 6C NPs were also larger than the succussed control 6C NPs. Details appear below.

In specific, NTA revealed the presence of nanoparticles in 20 of 21 test samples. The sole exception to the concentration findings was one succussed 6C control sample with no NPs detected on NTA.

To facilitate reporting the post-hoc tests, the following abbreviations are used: V6=verum Argentum Metallicum 6C, V30=verum Argentum Metallicum 30C, V200=verum Argentum Metallicum 200C; SC6=succussed control 6C; SC30=succussed control 30C; SC200=succussed control 200C; and UC=unsuccussed controls.

\section{Nanoparticle concentration findings}

The average concentrations of NPs were on the order of $10^{8}$ to $10^{9}$ nanoparticles per milliliter. Sample types differed significantly for NP concentrations overall (Table 1). Post-hoc tests revealed that the verum samples at $200 \mathrm{C}$ contained significantly higher NP concentrations than did the unsuccussed controls $(\mathrm{p}<0.05)$, with a trend for verum 200C toward more NPs than the succussed control 200C $(p=0.07)$. The succussed controls $30 \mathrm{C}$ also showed a trend toward greater NP concentrations than the unsuccussed controls $(\mathrm{p}<0.054)$.

\section{Nanoparticle size findings}

The mean sizes of the NPs in the verum and control samples differed significantly (Figure 1). On post-hoc Tukey tests, mean NP sizes in all of the 3 verum potencies were significantly larger than the unsuccussed controls. The $6 \mathrm{C}, 30 \mathrm{C}$, and $200 \mathrm{C}$ potencies of verum Argentum Metallicum were similar to each other in mean particle sizes on the NTA analysis.

The 7 different sample types also differed significantly overall for the standard deviations (SD) of their nanoparticle sizes $(\mathrm{F}(6,53)=9.17$, $\mathrm{p}<0.00001)$, with the highest SD variations in the verum $6 \mathrm{C}$ versus both its respective succussed control 6C (average standard deviations respectively V6 at $49.33 \mathrm{~nm}$ vs SC6 at $21.67 \mathrm{~nm}$ ), with post-hoc Tukey $\mathrm{p}=0.00022$ ) and the unsuccussed controls (UC average standard deviations at $23.67 \mathrm{~nm}$, post hoc Tukey versus V6C $\mathrm{p}=0.00012$ and UC versus V200C at $47.00 \mathrm{~nm}, \mathrm{p}=0.00034)$. The average $\mathrm{SD}$ for $\mathrm{NP}$ sizes at the verum $30 \mathrm{C}$ potency was $36.33 \mathrm{~nm}$ versus SC $30 \mathrm{C}$ at $29.33 \mathrm{~nm}$ ( $\mathrm{p}=0.77 \mathrm{~ns}$ ).

\begin{tabular}{|l|c|c|c|}
\hline Sample Type & $\begin{array}{c}\text { Mean NP } \\
\text { Concentration } \\
\text { (particles/ml, } \\
\text { corrected for dilution) }\end{array}$ & $\begin{array}{c}-95 \% \\
\text { Confidence } \\
\text { Interval }\end{array}$ & $\begin{array}{c}\mathbf{+ 9 5 \%} \\
\text { Confidence } \\
\text { Interval }\end{array}$ \\
\hline Argentum metallicum 6C & $4.864444 \mathrm{E}+08$ & $-2.647450 \mathrm{E}+08$ & $1.237634 \mathrm{E}+09$ \\
\hline Argentum metallicum 30C & $4.372222 \mathrm{E}+08$ & $-3.139672 \mathrm{E}+08$ & $1.188412 \mathrm{E}+09$ \\
\hline Argentum metallicum 200C & $19.78111 \mathrm{E}+08$ & $1.226922 \mathrm{E}+09$ & $2.729301 \mathrm{E}+09$ \\
\hline Succussed Control 6C & $3.012222 \mathrm{E}+08$ & $-4.499672 \mathrm{E}+08$ & $1.052412 \mathrm{E}+09$ \\
\hline Succussed Control 30C & $18.66667 \mathrm{E}+08$ & $1.115477 \mathrm{E}+09$ & $2.617856 \mathrm{E}+09$ \\
\hline Succussed Control 200C & $4.363222 \mathrm{E}+08$ & $-3.148672 \mathrm{E}+08$ & $1.187512 \mathrm{E}+09$ \\
\hline Unsuccussed Control & $2.622222 \mathrm{E}+08$ & $-4.889672 \mathrm{E}+08$ & $1.013412 \mathrm{E}+09$ \\
\hline
\end{tabular}

Overall ANOVA $F(6,56)=4.056, p=0.0019$; Tukey post-hoc tests ${ }^{*}(p<0.05)$ V200>UC, where $E+08$ signifies $10^{8}$ nanoparticles per milliliter

Table 1: Mean Concentrations of Nanoparticles by Nanoparticle Tracking Analysis Measurement. There were 3 samples of each sample type, and each sample was tested 3 times. 


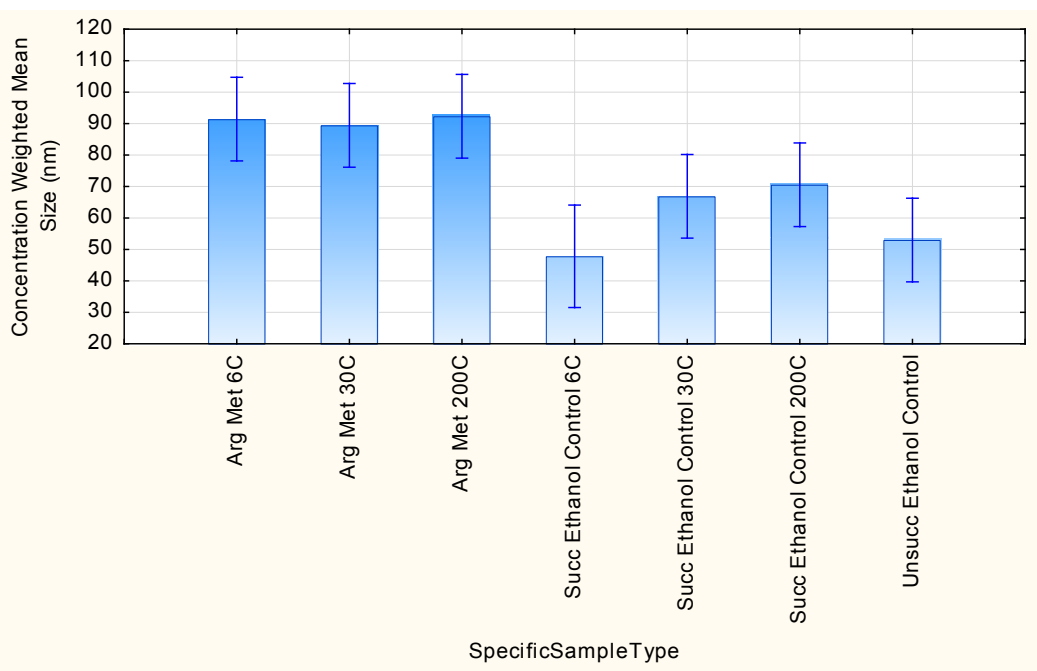

NTA=nanoparticle tracking analysis; Arg Met=Argentum Metallicum=Verum (V), always succussed at each potency (6C, 30C, 200C); Succ=Succussed Control (SC), always succcussed at each potency (6C, 30C, 200C); Unsucc (UC) = unsuccussed control; $n m=$ nanometers; $F(6,53)=6.975, p=0.00002$; post-hoc Tukey tests $(\mathrm{p}<0.05)$ : V6,V30, V200>UC; V6>SC6, where V6=verum Argentum metallicum 6C, V30=verum Argentum metallicum 30C, V200=verum Argentum metallicum 200C; SC6=succussed control 6C; SC30=succussed control 30C; SC200=succussed control 200C; and $\mathrm{UC}=$ unsuccussed controls.

Figure 1: NTA Mean Nanoparticle Sizes (nanometers) by Sample Types.

Figure 2 illustrates the polydispersity of sizes and optical heterogeneity of the nanomaterials, especially in the verum samples. This figure shows exemplar still shots from the 60-second NTA videos of Brownian motion for each type of sample (each vial was tested with 3 independent samples each, i.e., in triplicate). We chose the second video of the three recordings for the second randomized sample for each sample type. These screen captures may or may not always appear to correlate in a clearcut manner with the quantitative data averages. However, each still image represents only a split second out of the entire 60 second video recording for only one of 3 videos obtained on each of the 3 vials of each sample type.

\section{Zeta potentials}

The zeta potential data revealed greater stability (more negative values) in both low and high potency verum samples than in unsuccussed controls; the succussed control NPs at 30C were also more stable (more negative zeta potential values) than the NPs in the unsuccussed controls.

In specific, 20 of the 21 samples assessed with the Malvern Zetasizer instrument contained nanoparticles. The exception with this equipment was one succussed control 200C vial, which showed no detectable particles in this phase of the testing (performed 1 month after the completion of the NTA). All of the samples with particles exhibited a negative (anionic) zeta potential consistent with fair to good surface stability.

Figure 3 illustrates the overall significant sample type differences in mean zeta potential (millivolts, $\mathrm{mV}$ ). The unsuccussed controls tended to be the least stable by zeta potential tests (zeta=-20.21 mV). Verum 6C (zeta $=-43.92 \mathrm{mV}$ ) and verum 200C (zeta $=-39.06 \mathrm{mV})$ had significantly more negative mean zeta potentials (greater stability [83]) compared with the unsuccussed controls, with a trend for the succussed controls $30 \mathrm{C}$ toward more negative (more stable) zeta potential values compared with unsuccussed controls.

\section{UV-Visible spectroscopy}

UV-vis spectroscopy data revealed that the verum and succussed control samples all had greater average absorbance than did the unsuccussed controls. In addition, the findings indicated evidence for a progressive decrease in average absorbance values as a function of potency across both verum and succussed control samples. That is, within verums and within succussed controls, the lower potencies exhibited higher absorbances and the higher potencies exhibited lower absorbances. However, the unsuccussed controls had the lowest absorbances of all types of samples. The spectra per se revealed additional wavelength-related information, including higher absorbance in the $400-450 \mathrm{~nm}$ wavelength region for the verums versus both types of controls, i.e., consistent with the presence of a silver signal in the verums.

In specific, UV-vis spectral graphs revealed a large peak absorbance signal close to $200 \mathrm{~nm}$ wavelength with smaller peaks through approximately $350 \mathrm{~nm}$ wavelengths, notable in all samples (Figure 4 exemplars by sample type). Literature review suggested that these peaks could reflect organic plant material, e.g., from use of natural cork stoppers, rather than silver (whose peak, depending on particle size, should occur around 400-450 nm wavelengths, possibly red-shifted to longer wavelengths with silica present (http://nanocomposix.com/ pages/silver-nanoparticles-optical-properties).

At the same time, the verum silver potencies exhibit a higher average absorbance specifically in the $400-450 \mathrm{~nm}$ region than the succussed and unsuccussed controls, consistent with the presence of silver and silica-silver core-shell nanoparticles in verum samples. The latter finding might relate to surface plasmon resonance absorbance of the silver NPs and silica-silver core-shell NPs that could be generated during succussions.

The only possible organic source of the large 200 up to $350 \mathrm{~nm}$ peak signals in the present samples as prepared was the natural cork 
Citation: Bell IR, Muralidharan S, Schwartz GE (2015) Nanoparticle Characterization of Traditional Homeopathically-Manufactured Silver (Argentum Metallicum) Medicines and Placebo Controls. J Nanomed Nanotechnol 6: 311. doi:10.4172/2157-7439.1000311
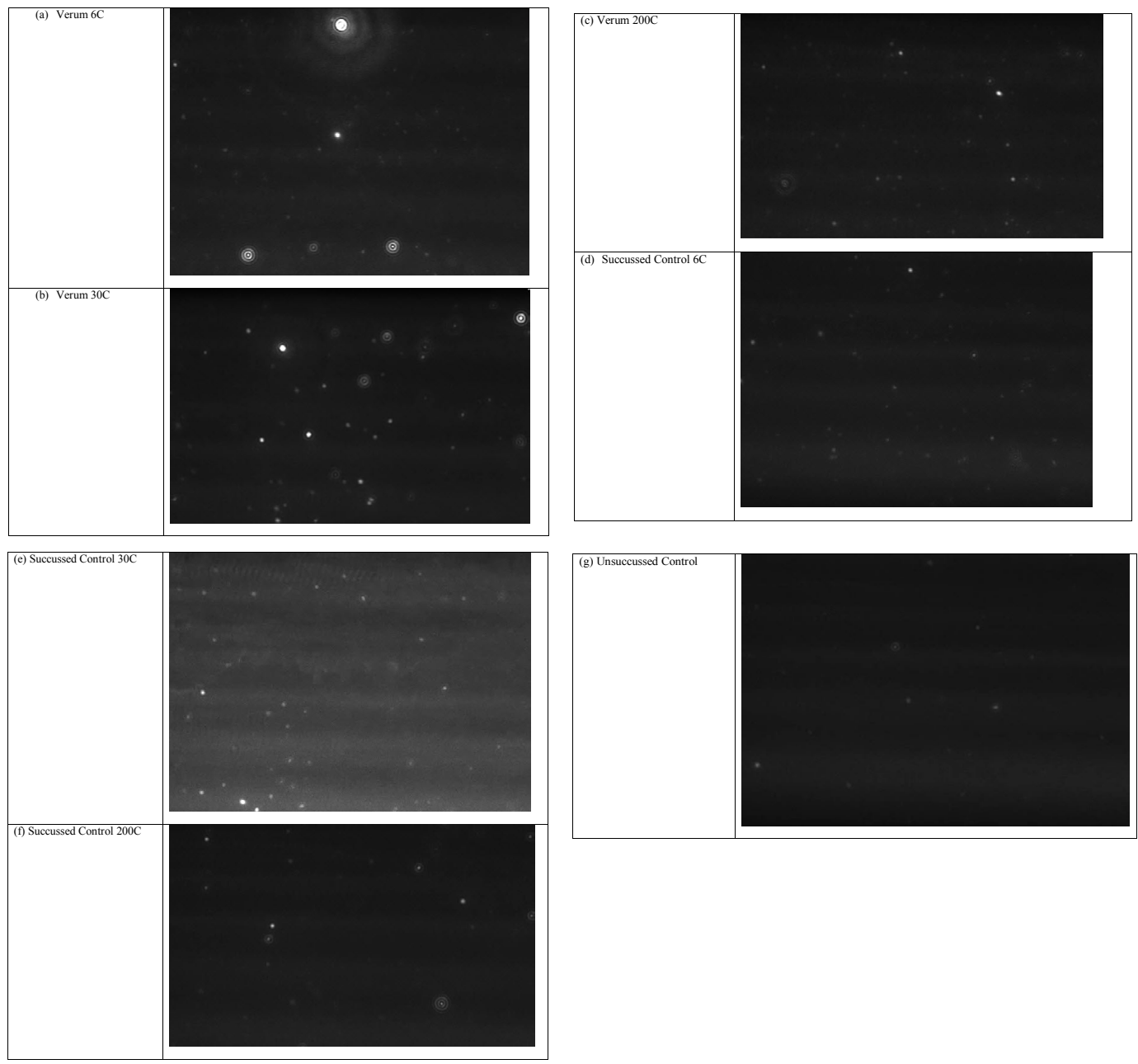

NTA=nanoparticle tracking analysis; Verum=Argentum Metallicum (silver)

Figure 2: Exemplar NTA Still Images from Videos of Brownian Motion of NPs for Verums, Succussed Controls, and Unsuccussed Controls.

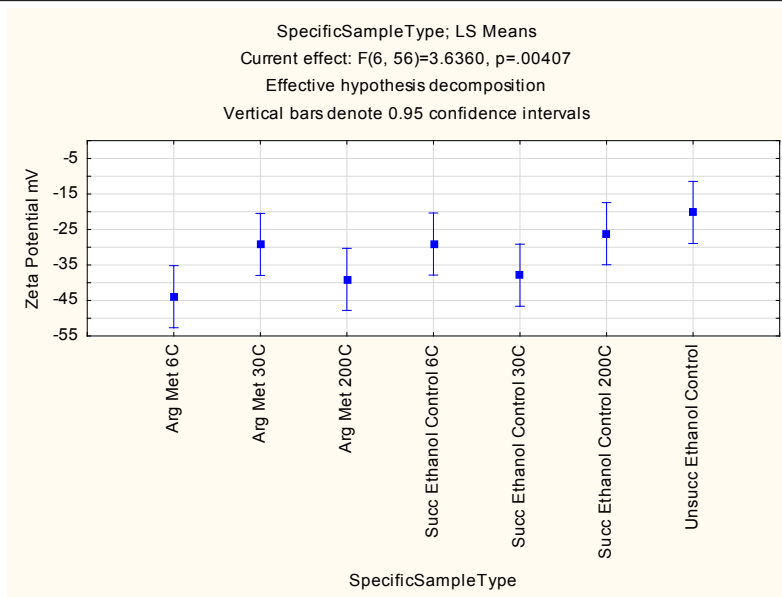

$F(6,56)=3.64, p=0.004$; post-hoc Tukey $(p \leq 0.05)$ : V6, V200<UC; and SC $30 \mathrm{C}<\mathrm{UC}$ (trend at $\mathrm{p}=0.08$ ), where Arg Met=Argentum MetallicumVerum; Succ=succussed; Unsucc=unsuccussed; $\mathrm{mV}=$ =millivolts; V6=verum Argentum metallicum 6C, V30=verum Argentum metallicum 30C, V200=verum Argentum metallicum 200C; SC6=succussed control 6C; SC30=succussed control 30C; $\mathrm{SC200}=$ succussed control 200C; and UC=unsuccussed controls.

Figure 3: Nanoparticle Mean Zeta Potentials $(\mathrm{mV})$ by Sample Type.
(Quercus suber bark) used to stopper every vial. Lactose was only used in the dry trituration of the initial verums at very low potency (eg, 1C3C) and was not present in succussed or unsuccussed controls.

Apart from the obvious dominant peaks in the 200-350 $\mathrm{nm}$ wavelength range across all samples, however, two other significant observations emerge. The UV-vis data were analyzed at $25 \mathrm{~nm}$ wavelength intervals from 200-1000 nm using an overall oneway analysis of variance over all 7 types of sample composition and potencies. The overall ANOVA F test over the 7 sample types had to be significant at a $\mathrm{p}<0.001$ level or better to justify examination of posthoc Tukey tests. Although the study was exploratory, we wanted to reduce the risk of type 1 error.

The 7 different sample types did not differ significantly for absorbance magnitude (AU) for the 200-375 $\mathrm{nm}$ wavelength range.

However, there appears to be an absorbance edge in the verum 6 Cs starting at $400 \mathrm{~nm}$. As Figure 4 illustrates over increasingly longer wavelengths, the verum $6 \mathrm{C}$ samples showed significantly and consistently higher absorbance than all of the other sample types, beginning at $400 \mathrm{~nm}$ (apparently consistent with a small silver NP peak). The verum $6 \mathrm{C}$ absorbance remained low and plateaued, but significantly higher on posthoc Tukey tests $(\mathrm{p}<0.05)$ than any other 

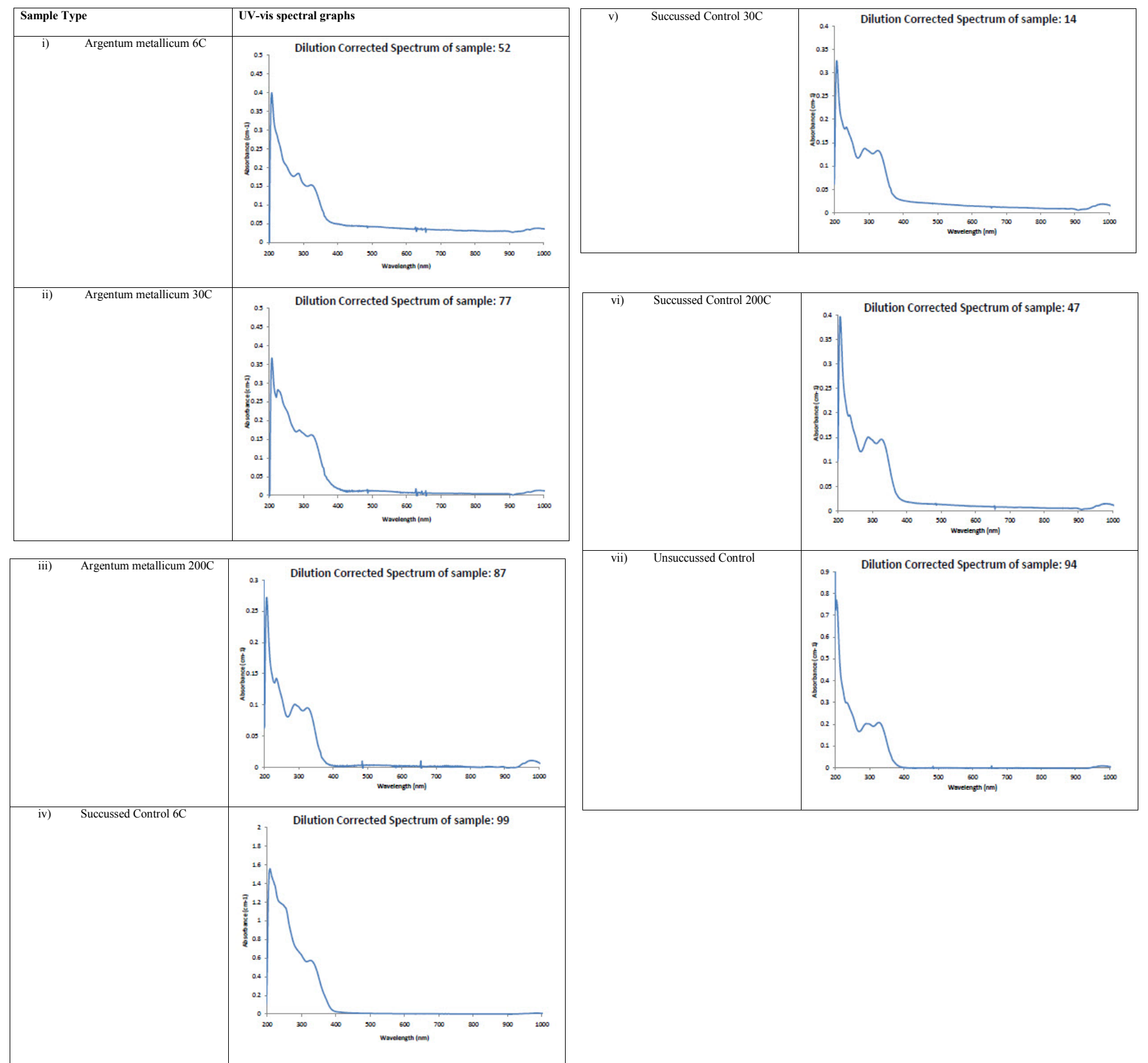

$\mathrm{nm}=$ nanometers

Figure 4: Exemplar UV-Vis spectroscopy spectra for each type of sample tested.

sample type from $400 \mathrm{~nm}$ through the $1000 \mathrm{~nm}$, ie, towards near infrared wavelengths. The rest of the wavelength data patterns and right-shift of the UV-vis in the $6 \mathrm{C}$ verum suggests the possibility of a mixture of silver NPs, as well as possibly silica-coated silver NPs and perhaps coreless-free silica NPs for which the silica coat thickness varied.

Second, a homeopathic potentization effect for both verums and succussed controls versus unsuccussed controls appears also to have occurred in the near infrared wavelength range. Visual inspection of the curves for the $30 \mathrm{C}$ and $200 \mathrm{C}$ potencies of both verum and succussed control samples exhibited another smaller but distinct rise in absorbance in the near infrared range from 950-1000 nm (consistent with the peak absorbance of water at $975 \mathrm{~nm}[84,85]$ ). Post-hoc Tukey tests confirmed statistically greater absorbance for the succussed controls $30 \mathrm{C}$ versus the unsuccussed controls, starting at $750 \mathrm{~nm}$ consistently through $1000 \mathrm{~nm}$ wavelengths. This finding was less consistent, but showed either significance or a strong trend for the succussed control 30C samples versus the unsuccussed controls beginning at $400 \mathrm{~nm}$ up to the $750 \mathrm{~nm}$, when it became consistent.

Sample types did not differ significantly overall in average maximum peak wavelength or absorbance at the peak wavelength. However, they did differ significantly in the patterns of average total absorbance over all wavelengths (190-1100 nm) as a function of potency level (Figure 5). Total absorbance over all wavelengths was highest in the lower potency 


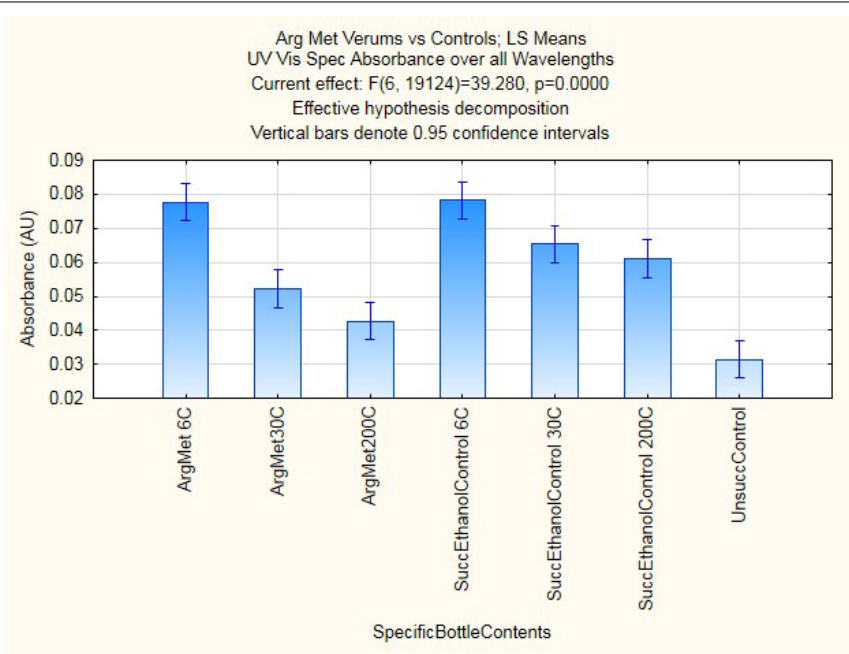

Verum $(V)=$ ArgMet, Argentum Metallicum (silver); Succ = SuccussedContro $(\mathrm{SC}) ;$ Unsucc $=$ Unsuccussed Control (UC) $(\mathrm{F}(6,19124)=39.3, \mathrm{p}<0.0001)$. Significant post hoc tests (where V6=verum 6C; V30=verum 30C; V200=verum 200C; SC6=succussed control 6C; SC30=succussed control $30 \mathrm{C}$ $\mathrm{SC} 200=$ succussed control 200C; UC=unsuccussed control): $\mathrm{V} 30<\mathrm{SC} 30$ V200<SC200; V6, V30, SC6, SC30>UC ( $<<0.03$ or better); trend for V200>UC $(p=0.066)$. SC6, SC30, SC200 $>$ UC (all $p<0.00003$ ).

Figure 5: Mean UV-vis spectroscopy absorbance over all wavelengths measured (each datapoint $=1 \mathrm{~nm}$ wavelength increments). All samples in ethanol $95 \% \mathrm{v} / \mathrm{v}$ solutions.

verum and succussed controls at $6 \mathrm{C}$ and lowest in the unsuccussed control.

On post-hoc tests, the unsuccussed controls were significantly lower in average absorbance across all wavelengths compared with verum potencies $6 \mathrm{C}$ and $30 \mathrm{C}(\mathrm{p}<0.0001)$, with a similar trend toward significance $(\mathrm{p}=0.066)$ for verum $200 \mathrm{C}$ and compared with all of the succussed control potencies $(6 \mathrm{C}, 30 \mathrm{C}, 200 \mathrm{C})(\mathrm{p}<0.0001)$.

\section{ICP-MS findings}

Despite repeated efforts, it was not possible to detect silver consistently in the samples with the lower limits of detection possible for the equipment used. Because of testing requirements, despite very low silver concentrations per unit volume, the samples were diluted in water to obtain sufficient volume to run the equipment. The measured silver quantities in the diluted test samples were all below $1 \mathrm{ppb}$ except for one unsuccussed control sample with an extreme outlier value (measured $=2.047 \mathrm{ppb}$; analytical laboratory dilution-corrected value $=20.665 \mathrm{ppb}$ ). Initial ICP-MS testing showed silver values estimated (extrapolated after dilution) at the very low ppb range across many verum and control samples with no systemic differences (range 0 to $20.665 \mathrm{ppb}$ ). When detected, these values for silver were higher than that found with the calibration blank. However, the majority of samples as measured fell at or below the $1 \mathrm{ppb}$ lower limit of detection for the instrument for verums and controls. The two highest, non-reproducible initial measurements for silver occurred in an unsuccussed control (20.665 ppb) and a succussed control 30C sample (8.613 ppb).

The unusual number and pattern of 7 outlier samples in all types of samples out of 21 total samples prompted repeat testing of those 7 samples. None of the initial silver concentration findings replicated; all were 0 or close to 0 . Nanocomposix concluded that the quantities of elemental silver in the samples were not reliably detectable with procedures needed for running the ICP-MS equipment. We ruled out silver cross-contamination at the manufacturer's site because of the order of sample preparation (placebo controls were made first on one day, then verums). The lack of consistent silver detection across the types of samples and the inability to replicate any outlier values also cast doubt on low level reagent contamination [86] from water or ethanol as an explanation for the apparent low estimated levels of silver initially reported. Future ICP-MS, or preferably, ICP-OES (inductively-coupled plasma optical emission spectroscopy) or ICPAES (inductively-coupled plasma-atomic emission spectroscopy) testing may require extensive sample pre-concentration to achieve reliable measurements and quantitative estimates of source materials in homeopathic medicines [2]. Budgetary limitations precluded testing the samples for elemental silicon with ICP-MS or applying ICP-OES.

\section{Transmission electron microscopy}

After the UV-vis spectroscopy and ICP-MS data were completed, one exemplar verum 30C sample was chosen for TEM evaluation after pre-concentration procedures described in Methods above. For this specific verum sample, the initial silver ICP-MS value was $1.268 \mathrm{ppb}$ extrapolated from measured concentration, with a repeat ICP-MS extrapolated value of $0.214 \mathrm{ppb}$ ).

Figure 6 of TEM images, all from a single Verum 30C sample reveals a complex mixture of materials. The four images in Figure 6 reflect four different areas of the same grid examined on which the single Verum $30 \mathrm{C}$ sample was pre-concentrated as described above. Initial image direct magnification varied $(25,000 \mathrm{x}$ to $40,000 \mathrm{x}$ to $60,000 \mathrm{x})$, but for visual perspective, these cropped image exemplars share the same 50 $\mathrm{nm}$ scale size shown in the lower right corner of each image. These materials on TEM appear to include polydisperse darker nanoparticles consistent with the appearance of highly faceted spherical shapes and
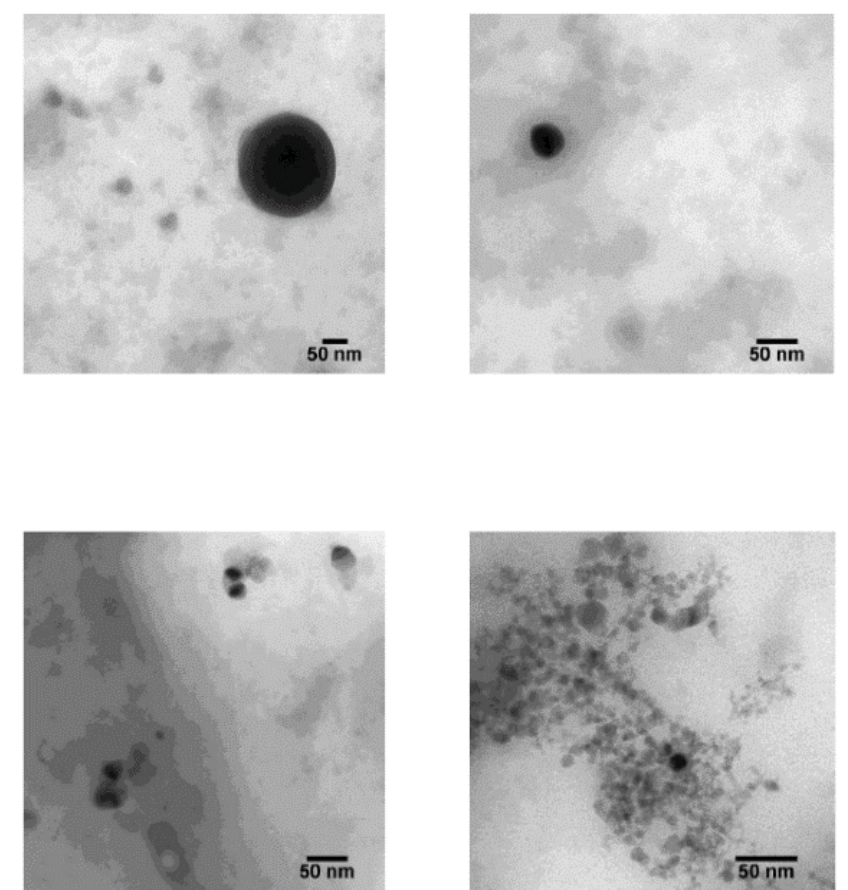

TEM=transmission electron microscopy; $\mathrm{nm}=$ nanometers

Figure 6: TEM images of one Verum Argentum Metallicum 30C preconcentrated sample. 
some irregularly shaped darker silver NPs embedded in an irregular, unstructured matrix of lighter gray background material (organic or another material). Budgetary limitations precluded performing additional TEM images of other samples, but TEM remains a priority for future investigations.

\section{Discussion}

To summarize the findings with the newer technology of nanoparticle tracking analysis, we demonstrated the presence of polydisperse nanoparticles in both traditional homeopathicallyprepared Argentum Metallicum (silver) verums and controls. The verum 200C samples exhibited significantly higher concentrations of NPs than did unsuccussed controls. Taken together with evidence from previous studies $[2-4,6-9,19,20]$, these data demonstrate that the present homeopathically-prepared silver medicines (Argentum Metallicum 6C, 30C, 200C) contain nanoparticles. Furthermore, the NPs in Argentum Metallicum verum samples differ from those in the control samples. The verum HMs not only contain nanostructures, but also exhibit unique particle characteristics in terms of larger sizes and more stable zeta potential values distinct from those of succussed solvent controls and especially of unsuccussed solvent controls.

The patterns of lower mean UV-vis spectroscopy absorbance as a function of increased numbers of succussions over increasing potencies of both verums and succussed controls suggest the possibility that the glass vials and natural corks were able to release more silicates and plant materials into solution when they were newest. The Korsakovian manufacturing process for higher potencies, reusing the same vials and stoppers over many serial dilution-succussion steps, could have led to progressive decreases in amounts of silicates from the glassware walls or cork stopper botanical materials available for release into solution from continued succussions. Unsuccussed samples, which had the lowest mean UV-vis absorbance, would have undergone much less agitation-caused release of silicates or plant materials into solution.

In specific, the current particle characterization techniques revealed:

(a) Verums exhibited the highest average concentrations of nanoparticles per milliliter (almost 2 billion NPs $/ \mathrm{ml}$ ) in the verum 200C potency samples versus the unsuccussed controls, although the succussed control 30C also contained almost 2 billion NPs/ml.

(b) Verum samples had significantly larger sized nanoparticles at all potencies compared with unsuccussed controls. The verum $6 \mathrm{C}$ samples also had significantly larger mean particle sizes and greater variability of particle sizes than their succussed control $6 \mathrm{C}$ counterparts.

(c) The highly negative zeta potentials of the verums indicate greater NP surface stability than that of NPs in the unsuccussed controls in particular.

(d) UV-absorbance data suggest that the material composition of the nanostructures in these samples is heterogeneous in nature, possibly including HM source silver, lactose in the triturated HM source silver samples, glassware-derived silica and other trace elements [21], cork (quercus suber plant material), ethanol and water itself.

(e) Compared with unsuccussed controls, higher potency verums and succussed controls at $30 \mathrm{C}$ and $200 \mathrm{C}$ showed UV-vis absorbance peaks at $975 \mathrm{~nm}$. This $975 \mathrm{~nm}$ wavelength peak is that of water [85]. Thus, as other investigators have considered [26,87], the dilutionsuccussion process per se appears to have enhanced the specific signal of water in the present samples $[12,26,88,89]$. (f) Overall, the TEM findings on the one verum 30C sample also suggest the presence of silver NPs together with some possibly hybrid silica-coated silver NPs with less electron-dense silica shells or adsorbed nanosilica, and some other lighter appearing nanostructures of indeterminate source material origins (perhaps organic and/or silica in nature, e.g., exosomes (organic nanosized particles) from the natural cork extract leached into solution.

In nanobiology and nanomedicine, presence or absence of NPs is not the only relevant variable. Specific particle characteristics can affect bioreactivity, e.g., particle sizes [90], shapes [91], and surface properties such as zeta potentials as markers of particle stability [92]. In fact, the current verum NPs differed from control NPs in these key particle parameters, including larger particle sizes on NTA and more negative zeta potential (more stable) values.

\section{Nanotechnology considerations}

Classical homeopathic manufacturing methods for Argentum Metallicum involve initial grinding of bulk silver source material in dry lactose followed by subsequent serial dilutions and succussions of ethanolic solutions within glass vials stoppered by natural corks (quercus suber, oak tree bark). It is thus possible that the early steps of prolonged milling of bulk silver formed lactose-capped core silver nanoparticles of relatively uniform sizes in the verum $6 \mathrm{C}, 30 \mathrm{C}$, and 200C samples. These lactose-coated core silver NPs would have transferred across all three types of verum potency samples [1], but should have been absent in all of the control samples.

Cork Stoppers-Potential Roles. At the same time, in all types of the present samples, quercus suber botanical extract from the natural cork stoppers and silica from the succussed vial glassware walls could have further contributed, respectively, organic reducing and capping agents, quercus plant exosomes (nanoscale sized vesicles of plant proteins, nucleic acids, and lipids), silica NPs, as well as surface-stabilizing silica coats for other NPs in the samples. Leaching of the original natural cork into solution could have initiated this process $[4,93,94]$.

Once in solution, the cork tree bark plant proteins (quercus suber) would likely form protein coronas around the surfaces of core silver and perhaps silica NPs [95]. The quercus suber particle coats could also have enlarged the sizes of the verum silver nanostructures observed with NTA vs TEM. However, as organic material from the corks [9699] would have added reducing and stabilizing capabilities for all sample types alike, cork by itself is not a sufficient explanation for the larger verum NP sizes of verum HMs versus control samples.

Based on the UV-vis absorbance differences in the current study and prior empirical studies $[100,101]$, the mechanical agitations from succussions of verums and succussed controls could be generating not only previously-reported silica NPs [22], but also plant exosomes [4] from oak tree bark quercus suber extract of the natural corks. These nanosized vesicles of organic plant materials would contain proteins, lipids, and micro RNA [94] and have the capacity to contribute biologically active antioxidant and anti-cancer nanostructures $[98,99,102,103]$, influence mammalian cells, and modulate biological function [94].

\section{Succussions, $\mathrm{pH}$, silicates, and trace element release from glass vials}

Alterations in solution $\mathrm{pH}$ from the succussion process could have affected the findings as well. For instance, $\mathrm{pH}$ differences from organic plant materials such as acids from the corks could cause increased 
absorbance in the near infrared wavelength range around the $975 \mathrm{~nm}$ peak of water [84] In releasing sodium from the borosilicate glass, Ives et al. showed that succussions foster formation of sodium bicarbonate, leading to an initial $\mathrm{pH}$ increase of the solution [6]. Subsequent succussions causes other changes that later neutralize the $\mathrm{pH}$ back toward 7.0 [10]. In turn, alkalinity of the solution will also affect the rate of dissolution of silicates from the glass surfaces of the container leading to a $\mathrm{pH}$-modulated silica gel layer at the interface of glass and solvent [6]. Finally, $\mathrm{pH}$ changes interacting with silica concentrations can affect the transition between gel and nanoparticle states [104]. Thus, succussion-related $\mathrm{pH}$ changes might contribute to a number of the current findings.

\section{Potential NP dopants}

Even earlier, Witt et al. [21] reported finding release of multiple trace element contaminants from brown glass containers during initial storage and the first potentization step from a homeopathic $1 \mathrm{C}$ mother tincture HM. The initial trace element "contamination" occurred within hours of contact between the solutions and the glassware. The most prevalent species that changed with sample age included: silicon, sodium, aluminum, iron, and magnesium. Polyethylene plastic containers did not produce the same contamination effects in the Witt et al. or subsequent studies that focused on measuring elemental silicon $[3,5,10]$. Using plastic containers or lining glassware with paraffin during production also reportedly reduces the biological effects of HMs [105]. These studies suggest that the silica NPs may be doped by other contaminants but present in any succussed material, with the dopants derived mainly from the glassware walls, whether or not natural cork stoppers are used. The present samples reflect the types of container (glass) and stopper (natural cork) materials that the founder of homeopathy, Samuel Hahnemann MD, would have had available to make the HMs that he first used for clinical treatment with his system of care.

A testable inference from the present evidence is that more succussions in glassware may lead to formation of greater numbers of micro- to nanoparticles of silica and any plant $[4,106]$ or animal material exosomes over time. Storage over time may have fostered the aging of NPs in solution, as previously reported in other homeopathic medicine studies [25]. The serial dilutions during manufacturing keep the nanoparticles separated from one another, thus initially lessening the risk of particle collisions and agglomeration. Still, in nanoscience, dilution of a more concentrated NP solution per se can change NP characteristics of the diluted forms, including surface properties in unpredictable ways [107].

\section{Possible silica-silver interactions}

Ives et al. $[10,108]$ originally proposed a silica model for the nature of homeopathic medicines. In vitro, plant, and animal studies have suggested some moderate biological activity even in succussed controls to an extent greater than unsuccussed controls $[10,21,23]$. Very small sized silica NPs formed during succussions could also interact with small silver NPs to contribute to the present findings in the verum samples. These might manifest with a flattened silver peak around $400 \mathrm{~nm}$ and cause the type of absorption edge starting at $400 \mathrm{~nm}$ wavelengths seen in the present UV-vis data for verum $6 \mathrm{C}$. The significantly lower UVvis absorbance for the $30 \mathrm{C}$ and $200 \mathrm{C}$ verums versus their respective controls could reflect formation of silicon dioxide (silica) and silver oxide nanoshells, as previously reported for nanocomposite films of silver NPs embedded in partially oxidized amorphous silicon matrix on silica glass [52].
The present findings suggest that classical homeopathic manufacturing materials and methods generate complex polydisperse nanoparticles and nanohybrids of not only source material (silver in this case), but also any materials used during the trituration (if performed), succussions and storage. These manufacturing materials include triturated or milled lactose (from initial manufacturing steps for metal based HMs); silicates from borosilicate glassware; if utilized, cork stopper extract (oak tree bark); and specific ethanol concentrations. It is well-established that variations in manufacturing parameters such as these factors can affect the sizes, shapes, and surface properties of silica and other types of nanoparticles $[20,109,110]$. Such factors could literally tune the optical, electromagnetic, chemical, and biological properties of the final product [111-114]. Notably, other laboratories have reported unique optical [28-30], electromagnetic [27,89], and thermal [27] properties in HM basic science studies. An important next research question would be to evaluate whether or not it is the NPs in verum HMs that generate these types of physical chemistry properties.

\section{Additional implications of uv-vis spectroscopy findings}

Previous studies suggest that the enhanced water signal in the UVvis data could derive from stronger hydrogen bonding to the oxygen of silanol (-OH) groups of mesoporous nanosilica in the succussed verum and succussed control samples $[11,12,115,116]$, in contrast with weaker hydrogen bonding typical of ordinary bulk water in unsuccussed controls [115]. Such data are consistent with both (a) Elia et al's report of nanostructured water in succussed homeopathically-prepared control solutions [6]; and (b) Cartwright's observation [11,12] of the dependence of the homeopathic signal propagation on silanol groups from the quartz (glassware) walls, an effect absent with polystyrene cuvettes.

The potential role of bulk water as solvent in HM manufacturing has historically received much attention. The controversial "memory of water" hypothesis for homeopathy might involve water in a final step when HMs are ultimately put into aqueous solutions [26]. However, the data to date suggest that the unique "signal" of specific HMs appears to depend more upon source [28-30,89] and silica nanostructures and glassware walls than on bulk water to propagate $[12,20,88]$. Very low potency Argentum Metallicum verum materials triturated or milled in dry lactose would not necessarily encounter water as a solvent during their initial manufacturing process. Furthermore, higher potency HMs made in ethanol or water solutions are routinely dried onto sugar pellets for storage and eventual administration $[29,30]$. Consequently, the nanostructures in HMs must persist intact after drying, an event that silica or metal NPs-but not bulk water-could survive [117-119].

\section{Limitations of current study}

The present study adds further support for a nanostructure model for HMs and their actions. However, various issues and additional questions arise. Ideally, the present study should have been performed at a single facility equipped with the specialized equipment and clean room areas needed to make and test the samples in the same facility. Shipping per se could have succussed the samples and affected the findings in the "unsuccussed" controls. However, all sample vials were packed and shipped together in the same box containers to minimize artifacts from any differences in handling during transport. This initial study design enabled evaluation of the same HM materials and methods used in clinical practice rather than an experimenter's version of homeopathic manufacturing in a laboratory.

Stricter control over sample age at the time of testing would have 
been highly preferable. Still, the tested samples were all made within the same two-day period, and randomization would have reduced any systematic bias effects on the laboratory testing data for different types of samples evaluated weeks apart. Rigorous repeat testing of the same samples over time is clearly needed in subsequent research. Marked increases in $\mathrm{pH}$ can increase calorimetric heat release and specific conductivity of homeopathic medicines at $15 \mathrm{C}$ versus control solution [120]. Assessing HM and control samples for any $\mathrm{pH}$ changes or differences that could foster formation of silica NPs from precursors is indicated [104]. Comparing NTA, DLS, and TEM for characterization of NPs in a full set of HMs, succussed and unsuccussed controls also would be useful.

Additional controls of triturated (dry milled) lactose in the ethanolwater solution would have been valuable to evaluate the relative contribution of milled lactose to the verum findings. Consistent with homeopathic manufacturing standards, the original silver source metal was initially triturated in dry lactose and then prepared in the liquid potencies as described. Presumably, as in Chikramane et al's investigation of gold NPs in HMs [1], lactose could have served in multiple roles to reduce, coat and cap the NPs [121], as well as to foster accumulation of NPs within certain layers of the subsequently succussed liquids for transfer between preparation steps [1].

Other controls using non-cork stoppers, different sizes and types of glassware, plastic containers, different ethanol and water concentrations, different methods of serial dilutions, different force and numbers of succussions all merit further testing [122]. However, budgetary and practical limitations precluded these additional procedures in this exploratory investigation.

Finally, future studies should not only characterize the nanoparticles in all $\mathrm{HM}$ and control samples as discussed above, but also evaluate the biological effects and therapeutic capabilities of well-characterized HM NPs (see below). Again, budgetary limitations precluded testing the specific samples in the current study for their biological or therapeutic activity. At the same time, as noted above, this specific manufacturer's verum HMs have shown differences from placebo controls in both previous basic science $[34,123]$ and clinical studies on human subjects $[72,74,75]$

\section{Implications for future biological effect studies}

In homeopathic practice, Argentum Metallicum is historically considered helpful in treating chronically ill individuals with a symptom pattern of nervousness, sensitivity, fatigue, weakness, and emaciation. Such patients may present with certain types of dypnoea and laryngeal symptoms along with gray mucus discharges [124]. Building upon the present NP data and prior physical chemistry studies $[2,29,30]$ of Argentum Metallicum, the clinical context may help guide future studies of the biological and therapeutic effects of this homeopathic medicine in individuals for whom it is salient. From a nanomedicine perspective, the observed differences in the present sample types for nanoparticle characteristics could lead to differences in biological effects between the Argentum Metallicum (silver) verums and controls when tested in future cell culture studies $[44,45,100,125]$ or clinical trials.

Like engineered NPs [126], specific HMs exhibit capacity to modulate gene expression patterns in multiple different biological systems [16,127-131]. Some investigators report that HMs also can emit source-related electromagnetic signals across short distances to influence bacteria or plant seedlings $[89,132]$. One research group has found that Argentum Metallicum in homeopathic potencies can produce unique optical signals with possible quantum effects, e.g., delayed photoluminescence [28-30].

Such findings overlap with a growing body of similar evidence on top-down and bottom-up synthesis of non-homeopathic nanoparticles $[56,93,133-136]$, their capacity for exerting biological or chemical effects at extraordinarily low concentrations [137-143], silica bioamplification [64-66,144,145], nano-opto-electronic tuning and amplification [52,58,64-66,68,146-153], and the propensity of NPs for aggregation [154], adsorption [107,155], self assembly[55,104,156], dilutional effects on surface reactivity $[107,155,157]$, cell signaling interactions [57-59,158-164], and aging phenomena [119,154,165,166].

With HMs, the ability of low doses of specific NPs to initiate biological effects in recipient living systems is a key consideration. As discussed in depth elsewhere [36-40,167,168], the biological effects of nanomaterials in HMs likely stem less from direct high-dose pharmacological actions of nanomedicines on drug receptors, and more from the indirect nonlinear biologically adaptive responses to lower doses by the recipient organism [39]. For instance, both NPs, including silver NPs [169-171], and homeopathically-prepared materials [172174] can elicit the low dose phenomenon of hormesis. The latter phenomenon has emerged as a leading model for homeopathic medicine effects $[175,176]$. Hormesis is defined as low dose stimulation and high dose inhibition of function in a biological system, manifested by biphasic, nonlinear dose response patterns $[39,169-171,177,178]$.

Hormesis depends on bioplasticity [177,179], i.e., the adaptive capacity of the recipient biological system itself to respond to external danger signals [169]. Detailed examination of the NP surface properties in verums and controls would advance understanding of how such nanomaterials could convey salient, hormetic adaptive signals to a specific living system [95]. For example, a recent nanotoxicology study of diesel exhaust and diesel doped with cerium dioxide NPs revealed that nanoparticle size $(60-120 \mathrm{~nm})$ and zeta potential $(-37$ to $-41 \mathrm{mV})$ were major factors in the bioreactivity of human immune cells [92]. Notably, the present verum HM NPs exhibited a comparable range of size and zeta potential characteristics.

The observed nonlinear magnification of the small source signal from specific HMs at higher homeopathic potencies in cells, plants, animals, and human beings [180-184] could stem from two interacting phenomena. These would include both the well-known ability of nanosilica to amplify weak signals $[62-64,66,185]$ and the capacity of recipient complex adaptive systems (CAS) such as cells or organisms to generate large magnitude, endogenously-amplified responses over time to very small salient external signals [186], e.g., specific predator odors or movements as examples [39,40]. The particle concentrations close to one billion NPs per milliliter observed in the present Argentum Metallicum verums, with particle sizes consistent with the nanoscale size ranges of viruses (10-150 nm), might also be sufficient to initiate immune cell activity within the biological cell defense response network [187-189]. As biological danger signals, NPs can trigger cell defense responses [189] as well as hormesis [169-171,178]

To trigger hormesis and other recipient organism-dependent response amplification processes, the HM treating agent in a low dose must serve as a salient danger signal, stressor, or biological threat to survival of the organism $[39,187]$. The signal itself has to be highly salient to the individual as a warning to initiate adaptive changes in function to strengthen the organism's resistance against future injuries from higher doses of the same or a cross-adapted agent or stressor 
$[169,190,191]$. Thus, future biological studies of NPs in HMs can begin by assessing signal properties of the agent, sensory and immune cell reactivity to the electromagnetic and optical signals emitted by the agent, and possible hormetic response effects on gene expression and cell defense response mechanisms.

\section{Conclusions}

The current NP findings and conclusions require additional rigorous and systematic study. Nevertheless, converging evidence from this and previous studies indicates that homeopathic medicines contain nanomaterials with sizes and surface properties different from those in succussed and unsuccussed controls. The composition and properties of those NPs in HMs need additional systematic research. The nanomaterials likely originate not only from manufacturer's dry milling of the original source material (silver) in lactose, but also from silicates and other trace elements/dopants released by succussions from the glassware walls. These materials also would interact with any other released materials (e.g., natural cork extract from stoppers) with the ability to adsorb and self assemble around the source NP cores.

If used as stoppers for the glassware, natural corks (quercus suber oak tree bark extracts) would further contribute (a) plant proteins to form a protein corona around the silver and/or silica NPs; (b) organic, biologically active nanosized plant exosomes formed mechanically during the multiple succussions for reducing and capping (stabilizing) nanomaterials that form; and (c) bottom up generation of additional silver NPs from any released silver ions [100] and nanosilica from silicates in solution off glassware walls as precursor agents [134]. Nanosilver made by plant extracts from botanical sources such as cork or other mother tinctures also used in homeopathic medicine (e.g., Thuja, Gelsemium, Hydrastis, Phytolacca, Ruta) can exert antibacterial and/or anti-cancer effects $[20,100,125,192]$.

Since all other factors were controlled in the succussed and unsuccussed control samples and all samples were made within the same two-day period, the interaction of the original lactose-milled silver with the other factors involved during manufacturing (succussions, glassware, natural cork (Quercus suber), 95\% ethanol-water solution) would appear to be the distinguishing feature of the present verum samples. Given the low but detectable quantities of the original source material in $\mathrm{HMs}$ at $6 \mathrm{C}, 30 \mathrm{C}$, and $200 \mathrm{C}$ potencies [2], hormesis [176] and other organism-dependent adaptive processes [39] are likely to be more central to the biological effects of nanoparticles in HMs than are direct higher-dose conventional pharmacological mechanisms.

Despite the comparatively crude nanotechnology manufacturing methods dating from the 1800's, the low concentrations, intermittent dosing schedules, and extensive safety record over 200 years of HMs in homeopathic practice [180] may still provide important clues for optimizing modern nanomedicine. Ultimately, a merging of concepts and best practices from both traditional and modern approaches could foster development of a safer, more effective integrative nanomedicine for the future $[38,167]$.

\section{Acknowledgement}

This nanoparticle characterization study was supported primarily by a grant from the AlterMed Research Foundation, Fort Collins, CO USA (PI: Dr. Bell) Additional funding for cancer-related nanoparticle research was provided by a grant from the Lotte and John Hecht Memorial Foundation, Vancouver, BC Canada (PI: Dr. Muralidharan; Consultant: Dr. Bell). The zeta potential analyses were performed in the Equipment Core Facility of the Simpson Querrey Institute at Northwestern University; the US Army Research Office, the US Army Medical Research and Materiel Command, and Northwestern University provided funding to develop this facility.
The authors also thank Dr. Rebecca Brewer, Scientific Advisor for the Alte rMed Research Foundation, and multiple homeopathic research colleagues at the American Medical College of Homeopathy and worldwide for their invaluable questions, comments, criticisms, and suggestions for study design and data interpretation.

\section{Disclosure}

Dr. Bell is a consultant to Standard Homeopathic/Hylands Inc, a U.S.-based manufacturer of homeopathic medicines. None of the company's products were evaluated in this study, and the company did not provide any financial assistance for the completion of the project or the publication of this paper. Dr. Muralidharan and Schwartz have no conflicts of interest to report.

\section{References}

1. Chikramane PS, Kalita D, Suresh AK, Kane SG, Bellare JR (2012) Why extreme dilutions reach non-zero asymptotes: a nanoparticulate hypothesis based on froth flotation. Langmuir 28: 15864-15875.

2. Chikramane PS, Suresh AK, Bellare JR, Kane SG (2010) Extreme homeopathic dilutions retain starting materials: A nanoparticulate perspective. Homeopathy 99: 231-242.

3. Upadhyay RP, Nayak C (2011) Homeopathy emerging as nanomedicine International Journal of High Dilution Research 10: 299-310.

4. Barve R, Chaughule R (2013) Size-dependent in vivo/in vitro results of homoeopathic herbal extracts. Journal of Nanostructure in Chemistry 3: 18.

5. Demangeat JL (2010) NMR relaxation evidence for solute-induced nanosized superstructures in ultramolecular aqueous dilutions of silica-lactose. Journal of Molecular Liquids 155: 71-79.

6. Elia V, Ausanio G, Gentile F, Germano R, Napoli E, et al. (2014) Experimental evidence of stable water nanostructures in extremely dilute solutions, at standard pressure and temperature. Homeopathy 103: 44-50.

7. Stovbun SV, Kiselev AV, Zanin AM, Kalinina TS, Voronina TA et al (2012) Effects of physicochemical forms of phenazepam and panavir on their action at ultra-low doses. Bull Exp Biol Med 153: 455-458.

8. Rajendran ES (2015) Field emission scanning electron microscopic (FESEM) and energy dispersive specroscopic (EDS) studies of centesimal scale potencies of the homeopathic drug Lycopodium clavatum. American Journal of Homeopathic Medicine 108: 9-18

9. Konovalov Al, Ryzhkina IS (2014) Highly diluted aqueous solutions: formation of nano-sized molecular assemblies (nanoassociates). Geochemistry International 52: 1207-1226.

10. Ives JA, Moffett JR, Arun P, Lam D, Todorov TI, et al. (2010) Enzyme stabilization by glass-derived silicates in glass-exposed aqueous solutions. Homeopathy 99: 15-24.

11. Cartwright S (2013) Pyridinium-N-phenolates as molecular probes of serially diluted and agitated solutions: preliminary results. 1st Homeopathic Research Institute, International Homeopathy Research Conference Cutting Edge Research in Homeopathy, Barcelona, May 31-June Spain.

12. Cartwright S (2014) Pyridinium-N-phenolates as molecular probes of serially diluted and agitated solutions: preliminary results. Homeopathy 103:65.

13. Fisher $P$ (2012) What is homeopathy? An introduction. Front Biosci (Elite Ed) 4: $1669-1682$

14. Bellavite P, Marzotto M, Chirumbolo S, Conforti A (2011) Advances in homeopathy and immunology: a review of clinical research. Front Biosci (Schol Ed) 3: 1363-1389.

15. Banerji P, Campbell DR, Banerji $P$ (2008) Cancer patients treated with the Banerji protocols utilising homoeopathic medicine: a Best Case Series Program of the National Cancer Institute USA. Oncol Rep 20: 69-74.

16. Frenkel M, Mishra BM, Sen S, Yang P, Pawlus A, et al. (2010) Cytotoxic effects of ultra-diluted remedies on breast cancer cells. Int J Oncol 36: 395-403.

17. Editorial (2005) The end of homoeopathy. Lancet 366: 690

18. Betti L, Trebbi G, Kokornaczyk O, Nani D, Peruzzi M, et al. (2013) Effectiveness of ultrahigh diluted arsenic is a function of succussion number as evidenced by wheat germination test and droplet evaporation method. Int J High Dilution Res 12: $127-128$ 
Citation: Bell IR, Muralidharan S, Schwartz GE (2015) Nanoparticle Characterization of Traditional Homeopathically-Manufactured Silver (Argentum Metallicum) Medicines and Placebo Controls. J Nanomed Nanotechnol 6: 311. doi:10.4172/2157-7439.1000311

19. Demangeat JL (2013) Nanosized solvent superstructures in ultramolecular aqueous dilutions: twenty years' research using water proton NMR relaxation. Homeopathy 102: 87-105.

20. Das S, Das J, Samadder A, Bhattacharyya SS, Das D, et al. (2013) Biosynthesized silver nanoparticles by ethanolic extracts of Phytolacca decandra, Gelsemium sempervirens, Hydrastis canadensis and Thuja occidentalis induce differential cytotoxicity through G2/M arrest in A375 cells. Colloids Surf B Biointerfaces 101: 325-336.

21. Witt CM, Lüdtke R, Weisshuhn TE, Quint $P$, Willich SN (2006) The role of trace elements in homeopathic preparations and the influence of container material storage duration, and potentisation. ForschKomplementmed 13: 15-21.

22. Liu L, Randolph TW, Carpenter JF (2012) Particles shed from syringe filters and their effects on agitation-induced protein aggregation. J Pharm Sci 101: 2952-2959.

23. Hostanska K, Rostock M, Melzer J, Baumgartner S, Saller R (2012) A homeopathic remedy from arnica, marigold, St. John's wort and comfrey accelerates in vitro wound scratch closure of NIH 3T3 fibroblasts. BMC Complement Altern Med 12: 100.

24. Elia V, Napoli E, Germano R (2007) The 'Memory of Water': an almost deciphered enigma. Dissipative structures in extremely dilute aqueous solutions. Homeopathy 96: 163-169.

25. Betti L, Elia V, Napoli E, Trebbi G, Zurla M, et al. (2011) Biological effects and physico-chemical properties of extremely diluted aqueous solutions as a function of aging-time. Frontiers in Life Science 5: 117-126.

26. Elia V, Marrari LA, Napoli E (2012) Aqueous nanostructures in water induced by electromagnetic fields emitted by EDS. Journal of Thermal Analysis and Calorimetry 107: 843-851.

27. Belon P, Elia V, Elia L, Montanino M, Napoli E, et al. (2008) Conductometric and calorimetric studies of the serially diluted and agitated solutions. Journal of Thermal Analysis and Calorimetry 93: 459-469.

28. Rey $L$ (2003) Thermoluminescence of ultra-high dilutions of lithium chloride and sodium chloride. Physica A: Statistical mechanics and its applications 323: 67-74.

29. Lenger K, Bajpai RP, Drexel M (2008) Delayed luminescence of high homeopathic potencies on sugar globuli. Homeopathy 97: 134-140.

30. Lenger K, Bajpai RP, Spielmann M (2014) Identification of unknown homeopathic remedies by delayed luminescence. Cell Biochem Biophys 68: 321-334.

31. Klein SD, Sandig A, Baumgartner S, Wolf U (2013) Differences in median ultraviolet light transmissions of serial homeopathic dilutions of copper sulfate, Hypericumperforatum, and sulfur. Evid Based Complement Alternat Med 2013: 370609.

32. Klein SD, Wolf U (2013) Investigating homeopathic verum and placebo globules with UV spectroscopy. Forsch Komplementmed 20: 295-297.

33. Marschollek B, Nelle M, Wolf M, Baumgartner S, Heusser P, et al. (2010) Effects of exposure to physical factors on homeopathic preparations as determined by ultraviolet light spectroscopy. Scientific World Journal 10: 49-61.

34. Rao ML, Roy R, Bell I (2008) Characterization of the structure of ultra dilute sols with remarkable biological properties. Mater Lett 62: 1487.

35. Wolf U, Wolf M, Heusser P, Thurneysen A, Baumgartner S (2011) Homeopathic preparations of quartz, sulfur and copper sulfate assessed by UV-spectroscopy. Evid Based Complement Alternat Med 2011: 692798.

36. Bell IR, Koithan M (2012) A model for homeopathic remedy effects: low dose nanoparticles, allostatic cross-adaptation, and time-dependent sensitization in a complex adaptive system. BMC Complement Altern Med 12: 191

37. Bell IR, Koithan M, Brooks AJ (2013) Testing the nanoparticle-allostatic crossadaptation-sensitization model for homeopathic remedy effects. Homeopathy 102: $66-81$.

38. Bell IR, Sarter B, Koithan M, Banerji P, Banerji P, et al. (2014) Integrative nanomedicine: treating cancer with nanoscale natural products. Glob Adv Health Med 3: 36-53.

39. Bell IR, Sarter B, Koithan M, Standish LJ, Banerji P, et al. (2013) Nonlinear response amplification mechanisms for low doses of natural product nanomedicines: dynamical interactions with the recipient complex adaptive system. J Nanomed Nanotechnol 4:179.
40. Bell IR, Schwartz GE (2013) Adaptive network nanomedicine: an integrated model for homeopathic medicine. Front Biosci (Schol Ed) 5: 685-708.

41. Niitsoo O, Couzis A (2011) Facile synthesis of silver core - silica shell composite nanoparticles. J Colloid Interface Sci 354: 887-890.

42. Filipe V, Hawe A, Jiskoot W (2010) Critical evaluation of Nanoparticle Tracking Analysis (NTA) by NanoSight for the measurement of nanoparticles and protein aggregates. Pharm Res 27: 796-810.

43. Sharma A, Purkait B (2012) Identification of medicinally active ingredien in ultradiluted Digitalis purpurea: fluorescence spectroscopic and cyclicvoltammetric study. J Anal Methods Chem 2012: 109058.

44. Sur I, Altunbek M, Kahraman M, Culha M (2012) The influence of the surface chemistry of silver nanoparticles on cell death. Nanotechnology 23: 375102.

45. Sur I, Cam D, Kahraman M, Baysal A, Culha M (2010) Interaction of multifunctional silver nanoparticles with living cells. Nanotechnology 21: 175104.

46. Araújo EA, Andrade NJ, da Silva LH, Bernardes PC, de C Teixeira AV, et al. (2012) Antimicrobial effects of silver nanoparticles against bacterial cells adhered to stainless steel surfaces. J Food Prot 75: 701-705.

47. Besinis A, De Peralta T, Handy RD (2012) The antibacterial effects of silver, titanium dioxide and silica dioxide nanoparticles compared to the dental disinfectant chlorhexidine on Streptococcus mutans using a suite of bioassays. Nanotoxicology.

48. Lara HH, Garza-Treviño EN, Ixtepan-Turrent L, Singh DK (2011) Silver nanoparticles are broad-spectrum bactericidal and virucidal compounds. $J$ Nanobiotechnology 9: 30

49. Antony JJ, Sithika MA, Joseph TA, Suriyakalaa U, Sankarganesh A, et al (2013) In vivo antitumor activity of biosynthesized silver nanoparticles using Ficusreligiosa as a nanofactory in DAL induced mice model. Colloids Surf B Biointerfaces 108: 185-190.

50. Rajasekharreddy P, Rani PU (2014) Biofabrication of Ag nanoparticles using Sterculiafoetida $L$. seed extract and their toxic potential against mosquito vectors and HeLa cancer cells. Mater SciEng C Mater BiolAppl 39: 203-212.

51. Siiman O, Jitianu A, Bele M, Grom P, Matijević E (2007) Amplified ligh scattering and emission of silver and silver core-silica shell particles. J Colloid Interface Sci 309: 8-20.

52. Mohapatra S, Mishra YK, Ghatak J, Kabiraj D, Avasthi DK (2008) Surface plasmon resonance of $\mathrm{Ag}$ nanoparticles embedded in partially oxidized amorphous Si matrix. J Nanosci Nanotechnol 8: 4285-4289.

53. Sukul NC, Ghosh S, Sukul A, Sinhababu SP (2005) Variation in Fourier transform infrared spectra of some homeopathic potencies and their diluent media. J Altern Complement Med 11: 807-812.

54. Rao ML, Roy R, Bell IR, Hoover R (2007) The defining role of structure (including epitaxy) in the plausibility of homeopathy. Homeopathy 96: 175-182.

55. Zhai C, Lu Q, Chen X, Peng Y, Chen L, et al. (2009) Molecularly imprinted layer-coated silica nanoparticles toward highly selective separation of active diosgenin from Dioscorea nipponica Makino. J Chromatogr A 1216: 2254-2262.

56. Kiel S, Grinberg O, Perkas N, Charmet J, Kepner H, et al. (2012) Forming nanoparticles of water-soluble ionic molecules and embedding them into polymer and glass substrates. Beilstein J Nanotechnol 3: 267-276.

57. Coll C, Bernardos A, Martínez-Máñez R, Sancenón F (2013) Gated silica mesoporous supports for controlled release and signaling applications. AccChem Res 46: 339-349.

58. Fang YS, Wang HY, Wang LS, Wang JF (2014) Electrochemical immunoassay for procalcitonin antigen detection based on signal amplification strategy of multiple nanocomposites. Biosens Bioelectron 51: 310-316.

59. Soster M, Juris R, Bonacchi S, Genovese D, Montalti M, et al. (2012) Targeted dual-color silica nanoparticles provide univocal identification of micrometastases in preclinical models of colorectal cancer. Int J Nanomedicine 7: 4797-4807.

60. Carmona-Ribeiro AM (2010) Biomimetic nanoparticles: preparation characterization and biomedical applications. Int J Nanomedicine 5: 249-259.

61. Neuhaus V, Chichester JA, Ebensen T, Schwarz K, Hartman CE, et al. (2014) A new adjuvanted nanoparticle-based $\mathrm{H} 1 \mathrm{~N} 1$ influenza vaccine induced antigenspecific local mucosal and systemic immune responses after administration into the lung. Vaccine 32: 3216-3222. 
Citation: Bell IR, Muralidharan S, Schwartz GE (2015) Nanoparticle Characterization of Traditional Homeopathically-Manufactured Silver (Argentum Metallicum) Medicines and Placebo Controls. J Nanomed Nanotechnol 6: 311. doi:10.4172/2157-7439.1000311

Page 14 of 16

62. Wang T, Jiang $\mathrm{H}$, Zhao Q, Wang S, Zou M, et al. (2012) Enhanced mucosal and systemic immune responses obtained by porous silica nanoparticles used as an oral vaccine adjuvant: effect of silica architecture on immunological properties. Int J Pharm 436: 351-358.

63. Demento SL, Eisenbarth SC, Foellmer HG, Platt C, Caplan MJ, et al. (2009) Inflammasome-activating nanoparticles as modular systems for optimizing vaccine efficacy. Vaccine 27: 3013-3021.

64. Mahony D, Cavallaro AS, Stahr F, Mahony TJ, Qiao SZ, et al. (2013) Mesoporous silica nanoparticles act as a self-adjuvant for ovalbumin model antigen in mice. Small 9: 3138-3146.

65. Al-Sadoon MK, Abdel-Maksoud MA, Rabah DM, Badr G (2012) Induction of apoptosis and growth arrest in human breast carcinoma cells by a snake (Walterinnesiaaegyptia) venom combined with silica nanoparticles: crosstalk between Bcl2 and caspase 3. Cell Physiol Biochem 30: 653-665.

66. Al-Sadoon MK, Rabah DM, Badr G (2013) Enhanced anticancer efficacy of snake venom combined with silica nanoparticles in a murine model of human multiple myeloma: Molecular targets for cell cycle arrest and apoptosis induction. Cell Immunol 284: 129-138.

67. Badr G, Al-Sadoon MK, Abdel-Maksoud MA, Rabah DM, El-Toni AM (2012) Cellular and molecular mechanisms underlie the anti-tumor activities exerted by Walterinnesia aegyptia venom combined with silica nanoparticles against multiple myeloma cancer cell types. PLoS One 7: e51661.

68. Zhuo Y, Yuan R, Chai YQ, Hong CL (2010) Functionalized $\mathrm{SiO}_{2}$ labeled CA19-9 antibodies: a new strategy for signal amplification of antigen-antibody sensing processes. Analyst 135: 2036-2042.

69. Li X, Niitsoo O Couzis A2 (2014) Experimental studies on irreversibility of electrostatic adsorption of silica nanoparticles at solid-liquid interface. J Colloid Interface Sci 420: 50-56.

70. Hahnemann S (1843) Organon of the medical art. (6thedn). Birdcage Books, Redmond, WA

71. Bell IR, Lewis DA 2nd, Brooks AJ, Lewis SE, Schwartz GE (2003) Gas discharge visualization evaluation of ultramolecular doses of homeopathic medicines under blinded, controlled conditions. J Altern Complement Med 9 : 25-38.

72. Bell IR, Lewis DA 2nd, Brooks AJ, Schwartz GE, Lewis SE, et al. (2004) Improved clinical status in fibromyalgia patients treated with individualized homeopathic remedies versus placebo. Rheumatology (Oxford) 43: 577-582.

73. Bell IR, Brooks AJ, Howerter A, Jackson N, Schwartz GE (2013) Acute electroencephalographic effects from repeated olfactory administration of homeopathic remedies in individuals with self-reported chemical sensitivity. Alternative Therapies in Health and Medicine 19: 46-57.

74. Bell IR, Howerter A, Jackson N, Aickin M, Baldwin CM, et al. (2011) Effects of homeopathic medicines on polysomnographic sleep of young adults with histories of coffee-related insomnia. Sleep Med 12: 505-511.

75. Bell IR, Brooks AJ, Howerter A, Jackson N, Schwartz GE (2011) Short-term effects of repeated olfactory administration of homeopathic sulphur or pulsatilla on electroencephalographic alpha power in healthy young adults. Homeopathy 100: 203-211.

76. Bell IR, Howerter A, Jackson N, Aickin M, Bootzin RR, et al. (2012) Nonlinear dynamical systems effects of homeopathic remedies on multiscale entropy and correlation dimension of slow wave sleep EEG in young adults with histories of coffee-induced insomnia. Homeopathy 101: 182-192.

77. Bell IR, Lewis DA 2nd, Lewis SE, Schwartz GE, Brooks AJ, et al. (2004) EEG alpha sensitization in individualized homeopathic treatment of fibromyalgia. In J Neurosci 114: 1195-1220.

78. Morrison R (1993) Desktop guide to keynotes and confirmatory symptoms. Hahnemann clinic publishing, Albany, CA.

79. Caron V, Willart JF, Lefort R, Derollez P, Danède F, et al. (2011) Solid state amorphization kinetic of alpha lactose upon mechanical milling. Carbohydr Res 346: 2622-2628.

80. Weber S, Endler PC, Welles SU, Suanjak-Traidl E, Scherer-Pongratz W, et al. (2008) The effect of homeopathically prepared thyroxine on highland frogs: influence of electromagnetic fields. Homeopathy 97: 3-9.

81. Bell NC, Minelli C, Tompkins J, Stevens MM, Shard AG (2012) Emerging techniques for submicrometer particle sizing applied to Stöber silica. Langmuir
28: $10860-10872$.

82. Soo CY, Song Y, Zheng Y, Campbell EC, Riches AC, et al. (2012) Nanoparticle tracking analysis monitors microvesicle and exosome secretion from immune cells. Immunology 136: 192-197.

83. Clogston JD, Patri AK (2011) Zeta potential measurement. Methods Mol Bio 697: 63-70.

84. Omar AF, Atan H, Matjafri MZ (2012) NIR spectroscopic properties of aqueous acids solutions. Molecules 17: 7440-7450.

85. Matcher SJ, Cope M, Delpy DT (1994) Use of the water absorption spectrum to quantify tissue chromophore concentration changes in near-infrared spectroscopy. Phys Med Biol 39: 177-196.

86. Arvela RK Leadbeater NE, Sangi MS, Williams VA, Granados P, et al. (2005) A reassessment of the transition-metal free suzuki-type coupling methodology. J Org Chem 70: 161-168.

87. Elia V, Napoli E (2010) Dissipative structures in extremely diluted solutions of homeopathic medicines: A Molecular model based on physico-chemical and gravimetric evidences. Int J Design Nature Ecodynamics 5: 39-48.

88. Cartwright S (2015) Solvatochromic dyes detect the presence of homeopathic potencies. 2nd HRI International Homeopathy Research Conference, June 9. Homeopathic Research Institute, Rome, Italy.

89. Montagnier L, Aïssa J, Ferris S, Montagnier JL, Lavallée C (2009) Electromagnetic signals are produced by aqueous nanostructures derived from bacterial DNA sequences. Interdiscip Sci Comput Life Sci 1: 81-90.

90. Shi Z, Huang X, Liu B, Tao H, Cai Y, et al. (2010) Biological response of osteosarcoma cells to size-controlled nanostructured hydroxyapatite. J BiomaterAppl 25: 19-37.

91. George S, Lin S, Ji Z, Thomas CR, Li L, et al. (2012) Surface defects on plateshaped silver nanoparticles contribute to its hazard potential in a fish gill cell line and zebrafish embryos. ACS Nano 6: 3745-3759.

92. Sarkar S, Zhang L, Subramaniam P, Lee KB, Garfunkel E, et al. (2014) Variability in bioreactivity linked to changes in size and zeta potential of diese exhaust particles in human immune cells. PLoS One 9: e97304.

93. Yi S, Wang Y, Huang Y, Xia L, Sun L, et al. (2014) Tea nanoparticles for immunostimulation and chemo-drug delivery in cancer treatment. J Biomed Nanotechnol 10: 1016-1029.

94. Mu J, Zhuang X, Wang Q, Jiang H, Deng ZB, et al. (2014) Interspecies communication between plant and mouse gut host cells through edible plant derived exosome-like nanoparticles. Mol Nutr Food Res 58: 1561-1573.

95. Walkey CD, Chan WC (2012) Understanding and controlling the interaction of nanomaterials with proteins in a physiological environment. Chem Soc Rev 41 2780-2799.

96. Da Silva AA, Do Nascimento ES, Cardoso DR, Franco DW (2009) Coumarins and phenolic fingerprints of oak and Brazilian woods extracted by sugarcane spirit. J Sep Sci 32: 3681-3691.

97. Cadahía E, Muñoz L, Fernández de Simón B, García-Vallejo MC (2001) Changes in low molecular weight phenolic compounds in Spanish, French, and American oak woods during natural seasoning and toasting. J Agric Food Chem 49: 1790-1798.

98. Popović BM, Stajner D, Zdero R, Orlović S, Galić Z (2013) Antioxidan characterization of oak extracts combining spectrophotometric assays and chemometrics. Scientific World Journal 2013: 134656.

99. Santos SAO, Pinto PCRO, Silvestre AJD, Neto CP (2010) Chemica composition and antioxidant activity of phenolic extracts of cork from Quercus suber L. Industrial Crops and Products 31: 521-526.

100. Chahardooli M, Khodadadi E, Khodadadi E (2014) Green synthesis of silve nanoparticles using oak leaf and fruit extracts (Quercus) and its antibacterial activity against plant pathogenic bacteria. International Journal of Biosciences 4: 97-103.

101. Judy JD, Tollamadugu P, Bertsch PM (2012) Pin Oak (Quercus palustris) Leaf extract mediated synthesis of triangular, polyhedral and spherical gold nanoparticles. Advances in Nanoparticles 1: 79-85.

102. Almeida T, Menéndez E, Capote T, Ribeiro T, Santos C, et al. (2013) Molecular characterization of Quercus suber MYB a transcription factor up-regulated in cork tissues. J Plant Physiol 170: 172-178. 
Citation: Bell IR, Muralidharan S, Schwartz GE (2015) Nanoparticle Characterization of Traditional Homeopathically-Manufactured Silver (Argentum Metallicum) Medicines and Placebo Controls. J Nanomed Nanotechnol 6: 311. doi:10.4172/2157-7439.1000311

Page 15 of 16

103. Fernandes A, Fernandes I, Cruz L, Mateus N, Cabral M, et al. (2009) Antioxidant and biological properties of bioactive phenolic compounds from Quercus suber L. J Agric Food Chem 57: 11154-11160.

104. Khan MN, Auerbach SM, Monson PA (2014) Lattice model for silica polymerization: Monte Carlo simulations of the transition between gel and nanoparticle phases. J Phys Chem B 118: 10989-10999.

105.Boiron C, Cier A, Vingert C (1968) Effets de quelquesfacteurs physiques surl'activitépharmacologiques de dilutions infinitésimales. Ann Hom Franc 10: 187-196.

106. Perry CC, Keeling-Tucker T (2003) Model studies of colloidal silica precipitation using biosilica extracts from Equisetum telmateia. Colloid Polym Sci 281: 652-664.

107. Chang X, Vikesland PJ (2013) Effects of dilution on the properties of nC60. Environ Pollut 181: 51-59.

108. Anick DJ, Ives JA (2007) The silica hypothesis for homeopathy: physical chemistry. Homeopathy 96: 189-195.

109. Yoo JW, Yun DS, Kim HJ (2006) Influence of reaction parameters on size and shape of silica nanoparticles. J Nanosci Nanotechnol 6: 3343-3346.

110. Abbasi AR, Morsali A (2012) Influence of solvents on the morphological properties of $\mathrm{AgBr}$ nano-structures prepared using ultrasound irradiation. Ultrason Sonochem 19: 540-545

111. Barreca D, Gasparotto A, Maragno C, Tondello E, Gialanella S (2007) Structure and optical properties of silica-supported Ag-Au nanoparticles. J Nanosci Nanotechnol 7: 2480-2486.

112. Chen Z, Chen X, Zheng L, Gang T, Cui T, et al. (2005) A simple and controlled method of preparing uniform Ag midnanoparticles on Tollens-soaked silica spheres. J Colloid Interface Sci 285: 146-151.

113. Ma Z Dong G, Peng M, Tan D, Zhang L, et al. (2013) Fabrication of silica nano/ micro-fibers doped with one-dimensional assembly of silver nanoparticles. J NanosciNanotechnol 13: 325-332.

114. Xia D, Li D, Ku Z, Luo Y, Brueck SR (2007) Top-down approaches to the formation of silica nanoparticle patterns. Langmuir 23: 5377-5385.

115. Pantalei C, Senesi R, Andreani C, Sozzani P, Comotti A, et al. (2011) Interaction of single water molecules with silanols in mesoporous silica. Phys Chem Chem Phys 13: 6022-6028.

116. Yang R, Wang F, Blunk RH, Angelopoulos AP (2010) Competing effects of silanol surface concentration and solvent dielectric constant on electrostatic layer-by-layer assembly of silica nanoparticles on gold. J Colloid Interface Sci 349: 148-152.

117. Baca HK, Carnes EC, Ashley CE, Lopez DM, Douthit C, et al. (2011) Celldirected-assembly: directing the formation of nano/bio interfaces and architectures with living cells. BiochimBiophysActa 1810: 259-267.

118. Bjornstrom J, Martinelli A, Johnson JRT, Matic A, Panas I (2003) Signatures of a drying $\mathrm{SiO}_{2} .\left(\mathrm{H}_{2} \mathrm{O}\right) \times$ gel from Raman spectroscopy and quantum chemistry. Chem Physics Lett 380:165-172.

119. Chaikin Y, Kedem O, Raz J, Vaskevich A, Rubinstein I (2013) Stabilization of metal nanoparticle films on glass surfaces using ultrathin silica coating. Anal Chem 85: 10022-10027.

120.Elia V, Niccoli M (1999) Thermodynamics of extremely diluted aqueous solutions. Ann N Y Acad Sci 879: 241-248.

121. Katti KK, Kattumuri V, Bhaskaran S, Katti KV, Kannan R (2009) Facile and General Method for Synthesis of Sugar Coated Gold Nanoparticles. Int $J$ Green Nanotechnol Biomed 1: B53-53B59.

122. Bhattacharyya SS, Mandal SK, Biswas R, Paul S, Pathak S, et al. (2008) In vitro studies demonstrate anticancer activity of an alkaloid of the plant Gelsemiumsempervirens. ExpBiol Med (Maywood) 233: 1591-1601.

123. Bell IR, Lewis D, Brooks AJ, Lewis S, Schwartz GE (2003) Gas discharge visualization evaluation of ultramolecular doses of homeopathic medicines under blinded, controlled conditions. Journal of Alternative and Complementary Medicine 9: 25-38

124. Kent JT (1972) Lectures on Homeopathic MateriaMedica. Jain Publishing Co. New Delhi, India.

125. Korbekandi H, Chitsazi MR, Asghari G, BahriNajafi R, Badii A, et al. (2015) Green biosynthesis of silver nanoparticles using Quercus brantii (oak) leaves hydroalcoholic extract. Pharm Biol 53: 807-812

126.Zollanvari A, Cunningham MJ, Braga-Neto U, Dougherty ER (2009) Analysis and modeling of time-course gene-expression profiles from nanomaterialexposed primary human epidermal keratinocytes. BMC Bioinformatics 10 Suppl 11: S10.

127. Bigagli E, Luceri C Bernardini S, Dei A, Filippini A, et al. (2014) Exploring the effects of homeopathic Apismellifica preparations on human gene expression profiles. Homeopathy 103: 127-132.

128. Khuda-Bukhsh AR, De A, Das D, Dutta S, Boujedaini N (2011) Analysis of the capability of ultra-highly diluted glucose to increase glucose uptake in arsenitestressed bacteria Escherichia coli. Zhong Xi Yi Jie He XueBao 9: 901-912.

129. Marzotto M, Olioso D, Brizzi M, Tononi P, Cristofoletti M, et al. (2014) Extreme sensitivity of gene expression in human SH-SY5Y neurocytes to ultra-low doses of Gelsemiumsempervirens. BMC Complement Altern Med 14: 104.

130. Preethi K, Ellanghiyil S, Kuttan G, Kuttan R (2012) Induction of apoptosis of tumor cells by some potentiated homeopathic drugs: implications on mechanism of action. Integr Cancer Ther 11: 172-182.

131. de Oliveira CC, de Oliveira SM, Goes VM, Probst CM, Krieger MA, et al (2008) Gene expression profiling of macrophages following mice treatment with an immunomodulator medication. J Cell Biochem 104: 1364-1377.

132. Baumgartner S, Betti L, Binder M, Heusser P, Wolf U (2015) Spatial allocation effects in a potentization basic research model - evidence for field-like effects of homeopathic preparations. 2nd HRI International Homeopathy Research Conference, Rome, Italy.

133. Merisko-Liversidge E, Liversidge GG (2011) Nanosizing for oral and parentera drug delivery: a perspective on formulating poorly-water soluble compounds using wet media milling technology. Adv Drug Deliv Rev 63: 427-440.

134.Perry CC, Keeling-Tucker T (1998) Crystalline silica prepared at room temperature from aqueous solution in the presence of intrasilicabioextracts. ChemCommun (Camb) 2587-2588.

135.Dipankar C, Murugan S (2012) The green synthesis, characterization and evaluation of the biological activities of silver nanoparticles synthesized from Iresineherbstii leaf aqueous extracts. Colloids Surf B Biointerfaces 98: 112-119.

136. Dwivedi AD, Gopal K (2011) Plant-mediated biosynthesis of silver and gold nanoparticles. J Biomed Nanotechnol 7: 163-164.

137. Comfort KK, Braydich-Stolle LK, Maurer El, Hussain SM (2014) Less is more: long-term in vitro exposure to low levels of silver nanoparticles provides new insights for nanomaterial evaluation. ACS Nano 8: 3260-3271.

138. Deraedt C, Astruc D (2014) "Homeopathic" palladium nanoparticle catalysis of cross carbon-carbon coupling reactions. AccChem Res 47: 494-503.

139. Diallo AK, Ornelas C, Salmon L, Ruiz Aranzaes J, Astruc D (2007) "Homeopathic" catalytic activity and atom-leaching mechanism in MiyauraSuzuki reactions under ambient conditions with precise dendrimer-stabilized Pd nanoparticles. Angew Chem Int Ed Engl 46: 8644-8648.

140. Shirali AC, Look M, Du W, Kassis E, Stout-Delgado HW, et al. (2011) Nanoparticle delivery of mycophenolic acid upregulates PD-L1 on dendritic cells to prolong murine allograft survival. Am J Transplant 11: 2582-2592.

141.Li X, Liu B, Li XL, Li YX, Sun MZ, et al. (2014) $\mathrm{SiO}_{2}$ nanoparticles change colour preference and cause Parkinson's-like behaviour in zebrafish. Sci Rep 4: 3810.

142. Bar-llan O, Chuang CC, Schwahn DJ, Yang S, Joshi S, et al. (2013) TiO nanoparticle exposure and illumination during zebrafish development: mortality at parts per billion concentrations. Environ SciTechnol 47: 4726-4733.

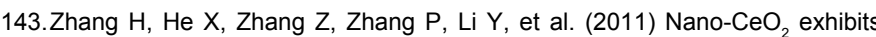
adverse effects at environmental relevant concentrations. Environ Sci Techno 45: $3725-3730$.

144. Kaehr B, Townson JL, Kalinich RM, Awad YH, Swartzentruber BS, et al. (2012) Cellular complexity captured in durable silica biocomposites. Proc Natl Acad Sci USA 109: 17336-17341.

145.Badr G, Al-Sadoon MK, El-Toni AM, Daghestani M (2012) Walterinnesiaaegyptia venom combined with silica nanoparticles enhances the functioning of normal lymphocytes through PI3K/AKT, NFÎB and ERK signaling. Lipids Health Dis 11: 27

146. Liu G, Lin Y (2007) Nanomaterial labels in electrochemical immunosensors 
Citation: Bell IR, Muralidharan S, Schwartz GE (2015) Nanoparticle Characterization of Traditional Homeopathically-Manufactured Silver (Argentum Metallicum) Medicines and Placebo Controls. J Nanomed Nanotechnol 6: 311. doi:10.4172/2157-7439.1000311

and immunoassays. Talanta 74: 308-317.

147.Brandenberger C, Rowley NL, Jackson-Humbles DN, Zhang Q, Bramble LA et al. (2013) Engineered silica nanoparticles act as adjuvants to enhance allergic airway disease in mice. Part FibreToxicol 10: 26.

148. Fine D, Grattoni A, Goodall R, Bansal SS, Chiappini C, et al. (2013) Silicon micro- and nanofabrication for medicine. AdvHealthc Mater 2: 632-666.

149. Xu J Liang J, Li J, Yang W (2010) Multicolor dye-doped silica nanoparticles independent of FRET. Langmuir 26: 15722-15725.

150. Feifel SC, Ludwig R, Gorton L, Lisdat F (2012) Catalytically active silica nanoparticle-based supramolecular architectures of two proteins--cellobiose dehydrogenase and cytochrome C on electrodes. Langmuir 28: 9189-9194.

151. McConnell MD, Kraeutler MJ, Yang S, Composto RJ (2010) Patchy and multiregionjanus particles with tunable optical properties. Nano Lett 10: 603609.

152. Weiping C, Lide Z (1997) Synthesis and structural and optical properties of mesoporous silica containing silver nanoparticles. Journal of Physics: Condensed Matter 9:725767.

153. Vanderkooy A, Chen Y, Gonzaga F, Brook MA (2011) Silica shell/gold core nanoparticles: correlating shell thickness with the plasmonic red shift upon aggregation. ACS Appl Mater Interfaces 3: 3942-3947.

154.Bagwe RP, Hilliard LR, Tan W (2006) Surface modification of silica nanoparticles to reduce aggregation and nonspecific binding. Langmuir 22 4357-4362.

155. Chang X, Vikesland PJ (2013) Uncontrolled variability in the extinction spectra of C60 nanoparticle suspensions. Langmuir 29: 9685-9693.

156. Belton DJ, Deschaume O, Perry CC (2012) An overview of the fundamentals of the chemistry of silica with relevance to biosilicification and technological advances. FEBS J 279: 1710-1720.

157. Mudunkotuwa IA, Grassian VH (2011) The devil is in the details (or the surface): impact of surface structure and surface energetics on understanding the behavior of nanomaterials in the environment. J Environ Monit 13: 1135-1144.

158. Marano F, Hussain S, Rodrigues-Lima F, Baeza-Squiban A, Boland S (2011) Nanoparticles: molecular targets and cell signalling. Arch Toxicol 85: 733-741.

159. Cervera J, Manzanares JA, Mafé S (2011) Sub-threshold signal processing in arrays of non-identical nanostructures. Nanotechnology 22: 435201.

160. Karig DK Siuti P, Dar RD, Retterer ST, Doktycz MJ, et al. (2011) Model for biological communication in a nanofabricated cell-mimic driven by stochastic resonance. Nano CommunNetw 2: 39-49.

161. Miao Y, Xu J, Shen Y, Chen L, Bian Y, et al. (2014) Nanoparticle as signaling protein mimic: robust structural and functional modulation of CaMKII upon specific binding to fullerene C60 nanocrystals. ACS Nano 8: 6131-6144.

162.Zhu M, Li Y, Shi J, Feng W, Nie G, et al. (2012) Exosomes as extrapulmonary signaling conveyors for nanoparticle-induced systemic immune activation. Small 8: 404-412.

163.Zhu M, Tian X, Song X, Li Y, Tian Y, et al. (2012) Nanoparticle-induced exosomes target antigen-presenting cells to initiate Th1-type immune activation. Small 8: 2841-2848.

164. Ristorcelli E, Beraud E, Verrando P, Villard C, Lafitte D, et al. (2008) Human tumor nanoparticles induce apoptosis of pancreatic cancer cells. FASEB J 22 3358-3369.

165. Gautam S, Dubey P, Gupta MN (2013) A facile and green ultrasonic-assisted synthesis of BSA conjugated silver nanoparticles. Colloids Surf B Biointerfaces 102: 879-883.

166. Liu Y, Kathan K, Saad W, Prud'homme RK (2007) Ostwald ripening of betacarotene nanoparticles. Phys Rev Lett 98: 036102.

167.Bell IR, Sarter B, Standish LJ, Banerji P, Banerji P (2015) Low doses of traditional nanophytomedicines for clinical treatment: manufacturing processes and nonlinear response patterns. J Nanosci Nanotechnol 15: 4021-4038.

168. Bell IR, Schwartz GE, Boyer NN, Koithan M, Brooks AJ (2013) Advances in integrative nanomedicine for improving infectious disease treatment in public health. Eur J Integr Med 5: 126-140.

169. Iavicoli I, Calabrese EJ, Nascarella MA (2010) Exposure to nanoparticles and hormesis. Dose response 8: 501-517.
170. lavicoli I, Fontana L, Leso V, Calabrese EJ (2014) Hormetic dose-responses in nanotechnology studies. Sci Total Environ 487: 361-374.

171. Jiao ZH, Li M, Feng YX, Shi JC, Zhang J, et al. (2014) Hormesis effects of silver nanoparticles at non-cytotoxic doses to human hepatoma cells. PLoS One 9: e102564.

172. Van Wijk R, Wiegant FA (2010) Post conditioning hormesis and the homeopathic Similia principle: molecular aspects. Hum ExpToxicol 29: 561 565.

173. Wiegant FA, Prins HA, Van Wijk R (2011) Post conditioning hormesis put in perspective: An overview of experimental and clinical studies. Dose Response 9: 209-224.

174. Malarczyk E, Pazdzioch-Czochra M, Graz M, Kochmańska-Rdest J, JaroszWilko A, et al. (2011) Nonlinear changes in the activity of the oxygen-dependent demethylase system in Rhodococcus erythropolis cells in the presence of low and very low doses of formaldehyde. Nonlinear Biomed Phys 5: 9.

175. Dei A, Bernardini S (2015) Hormetic effects of extremely diluted solutions on gene expression. Homeopathy 104: 116-122.

176. Calabrese EJ, Jonas WB (2010) Homeopathy: clarifying its relationship to hormesis. Hum ExpToxicol 29: 531-536.

177. Calabrese EJ (2013) Hormetic mechanisms. Crit Rev Toxicol 43: 580-606.

178. Nascarella MA, Calabrese EJ (2012) A method to evaluate hormesis in nanoparticle dose-responses. Dose Response 10: 344-354.

179. Calabrese EJ, Mattson MP (2011) Hormesis provides a generalized quantitative estimate of biological plasticity. J Cell Commun Signal 5: 25-38.

180. Bornhoft G, Matthiessen PF (2011) Homeopathy in healthcare: effectiveness, appropriateness, safety, costs. Springer-Verlag, Berlin, Germany.

181. Witt C, Albrecht H (2009) New Directions in Homeopathy Research. KVC Verlag, Essen, Germany.

182. Bellavite P, Marzotto M, Olioso D, Moratti E, Conforti A (2014) High-dilution effects revisited. 2. Pharmacodynamic mechanisms. Homeopathy 103: 22-43.

183. Bellavite P, Marzotto M, Olioso D, Moratti E, Conforti A (2014) High-dilution effects revisited. 1. Physicochemical aspects. Homeopathy 103: 4-21.

184. Bellavite P, Olioso D, Marzotto M, Moratti E, Conforti A (2013) A dynamic network model of the similia principle. Complement Ther Med 21: 750-761.

185. Mody KT, Popat A, Mahony D, Cavallaro AS, Yu C, et al. (2013) Mesoporous silica nanoparticles as antigen carriers and adjuvants for vaccine delivery. Nanoscale 5: 5167-5179.

186. Bellavite $P$ (2003) Complexity science and homeopathy: a synthetic overview Homeopathy 92: 203-212

187.Bell IR, Schwartz GE, Frye J, Sarter B, Standish LJ (2015) Extending the adaptive network nanomedicine model for homeopathic medicine: nanostructures as salient cell danger signals for adaptation. Nanoscience and Technology 2(1): 1-22.

188. Buzea C, Pacheco II, Robbie K (2007) Nanomaterials and nanoparticles: sources and toxicity. Biointerphases 2: MR17-71.

189. Gallo PM, Gallucci S (2013) The dendritic cell response to classic, emerging, and homeostatic danger signals. implications for autoimmunity. Front Immunol 4: 138.

190. Matus S, Castillo K, Hetz C (2012) Hormesis: protecting neurons against cellular stress in parkinson disease. Autophagy 8: 997-1001.

191. Milisav I, Poljsak B, Suput D (2012) Adaptive response, evidence of crossresistance and its potential clinical use. Int J Mol Sci 13: 10771-10806.

192. Sivakamavalli J, Deepa O, Vaseeharan B (2014) Discrete nanoparticles of ruta graveolens induces the bacterial and fungal biofilm inhibition. Cell Commun Adhes 21: 229-238. 